\title{
Ocean Circulation under Globally Glaciated Snowball Earth Conditions: Steady-State Solutions
}

\section{Citation}

Ashkenazy, Yosef, Hezi Gildor, Martin Losch, and Eli Tziperman. 2014. "Ocean Circulation under Globally Glaciated Snowball Earth Conditions: Steady-State Solutions." Journal of Physical Oceanography 44 (1): 24-43. https://doi.org/10.1175/jpo-d-13-086.1.

\section{Permanent link}

http://nrs.harvard.edu/urn-3:HUL.InstRepos:41384980

\section{Terms of Use}

This article was downloaded from Harvard University's DASH repository, and is made available under the terms and conditions applicable to Open Access Policy Articles, as set forth at http:// nrs.harvard.edu/urn-3:HUL.InstRepos:dash.current.terms-of-use\#OAP

\section{Share Your Story}

The Harvard community has made this article openly available.

Please share how this access benefits you. Submit a story.

Accessibility 
1

2

3

The Fredy and Nadine Herrmann Institute of Earth Sciences, The Hebrew University of Jerusalem, Jerusalem, Israel

5

\section{Ocean circulation under globally glaciated Snowball Earth}

\author{
conditions: steady state solutions
}

\author{
Yosef Ashkenazy * \\ Ben-Gurion University, Midreshet Ben-Gurion, Israel
}

HeZI GILDOR

Martin Losch

Alfred-Wegener-Institut, Helmholtz-Zentrum für Polar- und Meeresforschung, Bremerhaven, Germany

6

\section{ELI TZIPERMAN}

Dept. of Earth and Planetary Sciences and School of Engineering and Applied Sciences, Harvard University, Cambridge, MA, USA

*Corresponding authors' address: Yosef Ashkenazy, Department of Solar Energy and Environmental Physics, BIDR, Ben-Gurion University, Midreshet Ben-Gurion, 84990, Israel.

E-mail:ashkena@bgu.ac.il;

Eli Tziperman, Dept. of Earth and Planetary Sciences and School of Engineering and Applied Sciences, Harvard University; 20 Oxford St, Cambridge, MA, 02138, USA.

E-mail:eli@eps.harvard.edu 
Between $\sim 750$ to 635 million years ago, during the Neoproterozoic era, the Earth experienced at least two significant, possibly global, glaciations, termed "Snowball Earth". While many studies have focused on the dynamics and the role of the atmosphere and ice flow over the ocean in these events, only a few have investigated the related associated ocean circulation, and no study has examined the ocean circulation under a thick ( $\sim 1 \mathrm{~km}$ deep) sea-ice cover, driven by geothermal heat flux. Here, we use a thick sea-ice flow model coupled to an ocean general circulation model to study the ocean circulation under Snowball Earth conditions. We first investigate the ocean circulation under simplified zonal symmetry assumption and find (i) strong equatorial zonal jets, and (ii) a strong meridional overturning cell, limited to an area very close to the equator. We derive an analytic approximation for the latitudedepth ocean dynamics and find that the extent of the meridional overturning circulation cell only depends on the horizontal eddy viscosity and $\beta$ (the change of the Coriolis parameter with latitude). The analytic approximation closely reproduces the numerical results. Threedimensional ocean simulations, with reconstructed Neoproterozoic continents configuration, confirm the zonally symmetric dynamics, and show additional boundary currents and strong upwelling and downwelling near the continents. 


\section{Introduction}

The Neoproterozoic Snowball events are perhaps the most drastic climate events in Earth's history. Between 750 and 580 million years ago (Ma), the Earth experienced at least two major, possibly global, glaciations (e.g., Harland 1964; Kirschvink 1992; Hoffman and Schrag 2002; Macdonald et al. 2010; Evans and Raub 2011). During these events (the Sturian and Marinoan ice ages), ice extended to low latitudes over both ocean and land. It is still debated whether the ocean was entirely covered by thick ice ("hard" Snowball) (e.g., Allen and Etienne 2008; Pierrehumbert et al. 2011), perhaps expect very limited regions of sea-ice free ocean, e.g., around volcanic islands (Schrag et al. 2001) (that could have provided a refuge for photosynthetic life during these periods), or whether the tropical ocean was partially ice free or perhaps covered by thin ice ("soft" Snowball) (e.g., Yang et al. 2012c).

The initiation, maintenance, and termination of such a climatic condition pose a firstorder problem in ocean and climate dynamics. One may argue that the Snowball state was predicted by simple energy balance models (EBMs) (Budyko 1969; Sellers 1969). Snowball dynamics also provide a test-case for our understanding of the climate system as manifested in climate models. Therefore, in recent years, these questions have been the focus of numerous studies and attempts to simulate these climate states using models with different levels of complexity. The role and dynamics of atmospheric circulation and heat transport, $\mathrm{CO}_{2}$ concentration, cloud feedbacks, and continental configuration have been studied (Pierrehumbert 2005; Le-Hir et al. 2010; Donnadieu et al. 2004a; Pierrehumbert 2002, 2004; Le-Hir et al. 2007). Recently, the effect of clouds, as well as the role of atmospheric and oceanic heat transports in the initiation of Snowball Earth events was studied; these studies were based on atmospheric GCMs and used different setups and configurations including different $\mathrm{CO}_{2}$ concentrations, different continental configurations, and different sea-ice dynamics (Yang et al. 2012c,b,a; Voigt and Abbot 2012; Abbot et al. 2012). It was concluded, e.g., that sea-ice dynamics has important role in the initiation of Snowball events (Voigt 
and Abbot 2012). Additionally, perceived difficulties in exiting a Snowball state by a $\mathrm{CO}_{2}$ increase alone motivated the study of the role of dust over the Snowball ice cover (Abbot and Pierrehumbert 2010; Le-Hir et al. 2010; Li and Pierrehumbert 2011; Abbot and Halevy 2010).

A simple scaling calculation of balancing geothermal heat input into the ocean with heat escaping through the ice by diffusion leads to an estimated ice thickness of $1 \mathrm{~km}$. The ice cover is expected to slowly deform and flow toward the equator to balance for sublimation (and melting at the bottom of the ice) at low latitudes and snow accumulation (and ice freezing at the bottom of the ice) at high latitude. The flow and other properties of such thick ice over a Snowball ocean ("sea glaciers", Warren et al. 2002) were examined in quite a few recent studies (Goodman and Pierrehumbert 2003; McKay 2000; Warren et al. 2002; Pollard and Kasting 2005; Campbell et al. 2011; Tziperman et al. 2012; Pollard and Kasting 2006; Warren and Brandt 2006; Goodman 2006; Lewis et al. 2007). Snowball Earth global ice cover is an extreme example within a range of multiple ice cover equilibrium states, which have been studied in a range of simple and complex models (e.g., Langen and Alexeev 2004; Rose and Marshall 2009; Ferreira et al. 2011). In contrast to these many studies of different climate components during Snowball events, the ocean circulation during Snowball events has received little attention. Most model studies of a Snowball climate used an ocean mixed layer model only (Baum and Crowley 2001; Crowley and Baum 1993; Baum and Crowley 2003; Hyde et al. 2000; Jenkins and Smith 1999; Chandler and Sohl 2000; Poulsen et al. 2001b; Romanova et al. 2006; Donnadieu et al. 2004b; Micheels and Montenari 2008). The studies that used full ocean General Circulation Models (GCMs) concentrated on the ocean's role in Snowball initiation and aftermath (Poulsen et al. 2001a; Poulsen and Jacob 2004; Poulsen et al. 2002; Sohl and Chandler 2007), or other aspects of Snowball dynamics in the presence of oceanic feedback (Voigt et al. 2011; Le-Hir et al. 2007; Yang et al. 2012c; Ferreira et al. 2011; Marotzke and Botzet 2007; Lewis et al. 2007; Voigt and Marotzke 2010; Abbot et al. 2011; Lewis et al. 2004, 2003). Yet none of these studies employing ocean 
GCMs accounted for the combined effects of thick ice cover flow and driving by geothermal heating. Ferreira et al. (2011) simulated an ocean under a moderately thick (200 m) ice cover with no geothermal heat flux, and calculated a non steady-state solution with near-uniform temperature and salinity. They described a vanishing Eulerian circulation together with strongly parameterized eddy-induced high latitude circulation cells.

With both the initiation (Kirschvink 1992; Schrag et al. 2002; Tziperman et al. 2011) and termination (Pierrehumbert 2004) of Snowball events still not well understood, and the question of hard vs. soft Snowball still unresolved (Pierrehumbert et al. 2011), our focus here is the steady state ocean circulation under a thick ice cover (hard Snowball). By examining ocean dynamics under such an extreme climatic state, we aim to better understand the relevant climate dynamics, and perhaps even provide constraints on the issues regarding soft vs. hard Snowball states.

To study the 3D ocean dynamics under a thick ice cover, it is necessary to have a twodimensional (longitude and latitude) ice-flow model, and this was recently developed by Tziperman et al. (2012), based on the ice-shelf equations of Morland (1987) and MacAyeal (1997), extending the 1D model of Goodman and Pierrehumbert (2003). This model is coupled here to the MITgcm (Marshall et al. 1997). Another challenge in studying the 3D ocean dynamics under a thick ice cover is that thick ice with lateral variations of hundreds of meters (as under Snowball conditions) poses a numerical challenge as standard ocean models cannot handle ice that extends through several vertical layers; we use the ice-shelf model of Losch (2008), which allows for this. An alternative, vertically scaled coordinates, was used by Ferreira et al. (2011).

This paper expands on results briefly reported in Ashkenazy et al. (2013) (hereafter AGLMST), and we report the details of the steady state ocean dynamics under a thick ice (Snowball) cover, analytically and numerically, when both geothermal heating and a thick ice flow are taken into account. We find the ocean circulation to be quite far from the stagnant pool envisioned in some early studies, and very different from that in any other period in 
Earth's history. In particular, the stratification is very weak as might be expected (Ferreira et al. 2011), and is dominated by salinity gradients due to melting and freezing of ice; we find a meridional overturning circulation that is confined to the equatorial region, significant zonal equatorial jets, and strong equatorial meridional overturning circulation (MOC).

The paper is organized as follows. We first describe the models and configurations used in this study (section 2). We then present the results of the latitude-depth ocean model coupled to a 1D (latitude) ice-flow model when geothermal heating is taken into account (section 3). Analytically approximated solutions of the 2D, latitude-depth ocean model are then presented (section 4). Section 5 presents sensitivity runs to study the robustness of both the numerical results and the analytical approximations, followed by the steady state results of a 3D ocean model coupled to a longitude-latitude 2D ice-flow model in section 6 . The results are discussed and summarized in section 7 .

\section{Model description}

\section{a. Ice-flow model}

The ice-flow model solves for the ice depth and velocity over an ocean as a function of longitude and latitude, in the presence of continents (Tziperman et al. 2012). The model extends the 1D model of Goodman and Pierrehumbert (2003), which was based on the Weertman (1957) formula for ice shelf deformation. Because this specific formulation cannot be extended to ice flow in two horizontal dimensions, we instead used the ice-shelf approximation (Morland 1987; MacAyeal 1997) that can be extended to two dimensions. The ice-shelf approximation implies a depth-independent ice velocity, and in addition, the vertical temperature profile within the ice is assumed to be linear (Goodman and Pierrehumbert 2003). The temperature at the upper ice surface and surface ice sublimation and snow accumulation are prescribed from the energy balance of Pollard and Kasting (2005) and are assumed to be constant in time. The temperature and melting/freezing rates at the bottom of the ice are 
calculated by the ocean model. The model's spatial resolution is set to that of the ocean, and the model is run in either 1D (latitude only) or 2D configurations, depending on the ocean model used; it is typically $1-2^{\circ}$.

\section{b. The ocean model-MITgcm}

We used the Massachusetts Institute of Technology general circulation model (MITgcm, Marshall et al. 1997), a free-surface, primitive equation ocean model that uses $z$ coordinates with partial cells in the vertical axis; we use a longitude-latitude grid. To account for the thick ice, we used the ice-shelf package of the MITgcm (Losch 2008) that allows ice thicknesses that span many vertical layers. Parameter values followed Losch (2008). The ocean was forced at the bottom with a spatially variable (but constant in time) geothermal heat flux. The equation of state used here (Jackett and McDougall 1995) was tuned for the present day ocean, while the temperature and salinity we used to simulate Snowball conditions were somewhat outside this range. Sensitivity tests, using mean present day salinity and mean salinity that is two times larger than the present day value, showed no sensitivity of the results for the circulation. The ocean model was run at two different configurations, including a zonally symmetric 2D configuration and a near-global 3D configuration, described as follows.

\section{1) Latitude-DePth CONFiguration}

In the $2 \mathrm{D}$ runs, the spatial resolution was $1^{\circ}$ with 32 vertical levels spanning a depth of $3000 \mathrm{~m}$, with vertical level thicknesses (from top to bottom) of $920,15 \times 10,12,17,23$, $32,45,61,82,110,148,7 \times 200 \mathrm{~m}$; the uppermost level was entirely within the ice. The steady state ice thickness was calculated by the ice model to be approximately $1 \mathrm{~km}$ with lateral variations of less than $100 \mathrm{~m}$. The latitudinal extent of the 2D configuration was from $84^{\circ} \mathrm{S}$ to $84^{\circ} \mathrm{N}$ with walls specified at these boundaries to avoid having to deal with the polar singularity of the spherical coordinates. The bathymetry was either flat or had a Gaussian 
ridge centered at $\phi_{0}$ with a height of $h_{0}=1500 \mathrm{~m}$ and width $\sqrt{2} \sigma=7^{\circ}$ :

$$
h(\phi)=h_{0} e^{-\left(\phi-\phi_{0}\right)^{2} /\left(2 \sigma^{2}\right)} .
$$

In the standard configuration, the ridge was located at $\phi_{0}=20^{\circ} \mathrm{N}$, to schematically represent paleoclimatic estimates of more tectonic divergence zones in the Northern Hemisphere (NH). We choose the bottom geothermal heat flux to have the same form of Eq. (1) such that it is proportional to the height of the ridge (Stein and Stein 1992). The maximal geothermal heating was four times larger than the background, with a spatial mean value of $0.1 \mathrm{~W} / \mathrm{m}^{2}$, as for present day; in the standard 2D run presented below, the maximal geothermal heat was $\sim 0.3 \mathrm{~W} / \mathrm{m}^{2}$ while the background geothermal heat, far from the ridge, was $\sim 0.08 \mathrm{~W} / \mathrm{m}^{2}$. The mean value of $0.1 \mathrm{~W} / \mathrm{m}^{2}$ was based on the mean present day oceanic geothermal heat fluxes, given in Table 4 of Pollack et al. (1993).

The lateral and vertical viscosity coefficients were $2 \times 10^{4} \mathrm{~m}^{2} \mathrm{~s}^{-1}$ and $2 \times 10^{-3} \mathrm{~m}^{2} \mathrm{~s}^{-1}$. The lateral and vertical tracer diffusion coefficients were $200 \mathrm{~m}^{2} \mathrm{~s}^{-1}$ and $10^{-4} \mathrm{~m}^{2} \mathrm{~s}^{-1}$. To be conservative, the horizontal viscosity and diffusion coefficients were chosen to be larger than those estimated based on eddy resolving runs presented in AGLMST. Static instabilities in the water column were removed by increasing the vertical diffusion to $10 \mathrm{~m}^{2} \mathrm{~s}^{-1}$. Their large values required an implicit scheme for solving the diffusion equations. We note that our simulations do not incorporate the effect of vertical diffusion of momentum which was shown to be important in atmospheric dynamics under Snowball Earth conditions (Voigt et al. 2012).

For efficiency, we used the tracer acceleration method of Bryan (1984), with a tracer time step of 90 minutes and a momentum time step of 18 minutes. We did not expect major biases due to the use of this approach as time-independent forcing was used here. 


\section{2) 3D CONFIGURATION}

The domain of the $3 \mathrm{D}$ configuration was $84^{\circ} \mathrm{S}$ to $84^{\circ} \mathrm{N}$, again with walls specified at these boundaries, with a horizontal resolution of $2^{\circ}$. The ocean depth was $3000 \mathrm{~m}$, and there were 73 levels in the vertical direction with thicknesses (from top to bottom) of: $550 \mathrm{~m}$, 57 layers of $10 \mathrm{~m}$ each, 14, 20, 27, 38, 54, 75, 105, 147, and then 7 layers of $200 \mathrm{~m}$ each. In a steady state, the upper 33 levels were inside the ice - the high $10 \mathrm{~m}$ depth resolution was needed to resolve the relatively small variations in ice thickness. We used a reconstruction of the land configuration at $720 \mathrm{Ma}$ of Li et al. (2008). The standard run used a flat ocean bottom, reflecting the uncertainty regarding Neoproterozoic bathymetry. To address this uncertainty, we showed sensitivity experiments to bathymetry using prescribed Gaussian sills and ridges of $1 \mathrm{~km}$ height.

The average geothermal heat flux was $0.1 \mathrm{~W} \mathrm{~m}^{-2}$, as in the 2D case. The $720 \mathrm{Ma}$ configuration of Li et al. (2008) also included estimates of the location of divergence zones (ocean ridges). In these locations, the geothermal heat flux was up to four times the background; we also presented sensitivity runs with uniform geothermal heat flux and with additional geothermal heat flux at the ocean ridges.

The horizontal and vertical viscosity coefficients were $5 \times 10^{4} \mathrm{~m}^{2} \mathrm{~s}^{-1}$ and $2 \times 10^{-3} \mathrm{~m}^{2} \mathrm{~s}^{-1}$, respectively. The lateral and vertical diffusion coefficients for both temperature and salinity were $500 \mathrm{~m}^{2} \mathrm{~s}^{-1}$ and $10^{-4} \mathrm{~m}^{2} \mathrm{~s}^{-1}$. As in the $2 \mathrm{D}$ configuration, the implicit vertical diffusion scheme was used with an increased diffusion coefficient of $10 \mathrm{~m}^{2} \mathrm{~s}^{-1}$ in the case of statically unstable stratification. The tracer acceleration method (Bryan 1984) was used in these runs with a tracer time step of three hours and a momentum time step of 20 minutes.

\section{c. Initial conditions}

The initial ice thickness, both for the 2D and 3D ocean runs, was chosen with a balance between the geothermal heat flux of $0.1 \mathrm{~W} \mathrm{~m}^{-2}$ and the mean atmospheric temperature of 
$-44^{\circ} \mathrm{C}$ in mind. As the 3D ocean model runs were highly time consuming, we choose an initial ice-depth that is closer to the final steady state, instead of initiating the ocean model with an uniform ice-depth. The initial ice depth was calculated by running the much faster ice-flow model for thousands of years to a steady state when assuming zero melting at its base. For the zonally symmetric 2D ocean runs, the initial ice depth for the ocean model was chosen to be uniform in space.

Recent estimates of the mean ocean salinity in Snowball states lie somewhere between the present day value of $\sim 35$ and two times this value $(\sim 70)$ (although see Knauth 2005), based on the assumption that the ocean's Neoproterozoic salt content prior to the Snowball events was similar to present day values and that the mean ocean water depth was about two kilometers, about half of present day values. This is based on an assumed $1 \mathrm{~km}$ sea level equivalent land ice cover (Donnadieu et al. 2003; Pollard and Kasting 2004) and $1 \mathrm{~km}$ ice cover over the ocean. We chose (somewhat arbitrarily) an initial salinity of 50 . The initial temperature was set to be uniform and equal to the freezing temperature based on an ice depth of $1 \mathrm{~km}$ and the initial salinity described above, following Losch (2008),

$$
T_{f}=\left(0.0901-0.0575 S_{f}\right)^{o}-7.61 \times 10^{-4} p_{b},
$$

where $S_{f}$ is the freezing salinity (in our case, the initial salinity), and $p_{b}$ is the pressure at the bottom of the ice and is given in dBar. For an ice depth of $1 \mathrm{~km}$ and a salinity of 50, we obtained an initial temperature of about $-3.55^{\circ} \mathrm{C}$. For salinities of 35 and 70 , we obtained freezing temperatures of $\approx-2.7^{\circ} \mathrm{C}$ and $\approx-4.7^{\circ} \mathrm{C}$, respectively.

\section{d. Coupling the models}

The ice and ocean models were asynchronously coupled, each run for 300 years at a time. The ice thickness was fixed during the ocean run, at the end of which the melting rate at the base of the ice and the freezing temperature, calculated at each horizontal location by the ocean model, were passed to the ice-flow model. The ice model was then run to update 
the ice-thickness. The simulation ended after both models reached a steady state. Typically, more than 30 ice-flow-ocean coupling steps (9,000 years) were required.

\section{Zonally-averaged fields and MOC using a latitude- depth ocean model}

The ice thickness, the bottom freezing rate of the ice together with the atmospheric snow accumulation minus sublimation, and the ice velocity of the $2 \mathrm{D}$ configuration at steady state were already presented in AGLMST. The ice surface temperature and the net surface accumulation rate are symmetric about the equator (following Pollard and Kasting 2005), but the ice depth, the freezing rate at the bottom of the ice (calculated by the ocean model), and the ice velocity are not, because the enhanced geothermal heat flux over the ridge at $20^{\circ} \mathrm{N}$ leads to thinner ice, larger melting, and a smaller ice velocity in the $\mathrm{NH}$. The bottom ice melting rate is maximal in two locations: (i) $20^{\circ} \mathrm{N}$ due to the maximum geothermal heating, and (ii) at the equator due to the strong ocean dynamics (as will be shown below). The ice thickness is around $1150 \mathrm{~m}$ on average, and varies over a range of only about 80 $\mathrm{m}$. This small variation is due to the efficiency of the ice flow in homogenizing ice thickness (Goodman and Pierrehumbert 2003). The small variations in ice-thickness are consistent with previous studies (Tziperman et al. 2012; Pollard and Kasting 2005).

The density, and the vertical derivative of the density are plotted in Fig. 1a,b while the oceanic potential temperature and salinity of AGLMST are presented in the top panels of Fig. 2. Variations in temperature, salinity, and density are $\sim 0.3^{\circ} \mathrm{C}, \sim 0.5$, and $\sim 0.3 \mathrm{~kg} / \mathrm{m}^{3}$, respectively. The ocean temperature is low because the high pressure at the bottom of the $(\sim 1 \mathrm{~km})$ thick ice and the high salinity $(\sim 49.5)$ reduce the freezing temperature. The small variations in temperature at the top of the ocean (bottom of the ice), the large variations in surface salinity, the similarity between the density and salinity fields, and an analysis based on a linearized equation of state all indicate that changes in density are dominated by 
salinity variations. The changes in salinity are brought about by melting over the enhanced geothermal heat flux in the $\mathrm{NH}$ : the warmest water is close to the warm ridge, and the freshest water is located above the top of the ridge.

A notable feature of the solution is the vertically well-mixed water column, except in the vicinity of the geothermally heated ridge and the equator, where a very weak stratification exists. This weak stratification is associated with melt water at the base of the ice as a result of the enhanced heating there. This is also related to the zonal jets that are discussed below and in the next section. The nearly vertically homogeneous potential density is used to simplify the analytic analysis in the next section.

The zonal, meridional, vertical velocities, and the MOC, are shown in Fig. 1c,d and in the top panel of Fig. 2. Surprisingly, the counterclockwise circulation is concentrated around the equator, while velocities away from the equator, including over the ridge and enhanced heating, are very weak. This result is explained in the next section. The simulated currents are not small, as one would naively expect from a "stagnant" ocean under Snowball Earth conditions (Kirschvink 1992), and the intensity of the circulation is close to that of the present day.

Several additional features of the solution are worth noting: (i) there are two relatively strong and opposite (anti-symmetric) jets (of a few $\mathrm{cm} \mathrm{s}^{-1}$ ) in the zonal velocity, $u$ (top panel of Fig. 2). At the surface, we observe a westward current north of the equator and an eastward current south of the equator. The meridional velocity (Fig. 1c) is symmetric around the equator, with negative (southward) direction at the top of the ocean and positive (northward) direction at the bottom of the ocean. (ii) The zonal and meridional velocities are maximal (minimal) at the top and the bottom of the ocean, change sign with depth, and vanish at the middle of the ocean. (iii) Both the zonal and meridional velocities decay away from the equator where the zonal velocity decays much slower than the meridional and vertical velocities. (iv) The MOC (top panel of Fig. 2) stream function, implied by the vertical and meridional velocities, is largest at the equator and concentrated close to the 
equator. (v) The vertical velocity $w$ (Fig. 1d) is upward (positive) north of the equator, downward (negative) south of the equator, vanishes at the equator and maximal at mid ocean depth.

\section{The dynamics of the equatorial MOC and zonal jets}

Our goal in this section is to explain the dynamical features listed in the previous section. We consider the steady state, zonally symmetric ( $x$-independent) hydrostatic equations. For simplicity, we use a Cartesian coordinate system centered at the equator with an equatorial $\beta$ plane approximation. Then, following the numerical simulations, the advection and vertical viscosity terms can be neglected from the momentum equations (not shown). Apart from the fact that they are found to be small in the numerical simulation, the momentum advection terms and the vertical viscosity may be shown to be small based on scaling arguments (see Appendix). Based on the numerical results presented in section 3 and Fig. 1a, the density is assumed to be independent of depth and the meridional density (pressure) gradient is assumed to be approximately constant near the equator.

The dominant momentum balances are found to be

$$
\begin{aligned}
-\beta y v & =\nu_{h} u_{y y}, \\
\beta y u & =-p_{y} / \rho_{0}+\nu_{h} v_{y y}, \\
p_{z} & =-g \rho,
\end{aligned}
$$

where $y$ and $z$ are the meridional and depth coordinates, $u$ and $v$ are the zonal and meridional velocities, $\beta=d f / d y$ (where $f$ is the Coriolis parameter), $\nu_{v}$ and $\nu_{h}$ are the vertical and horizontal eddy-parameterized viscosity coefficients, $\rho$ is the density, $\rho_{0}$ is the mean ocean density, and $g$ is the gravity constant. Vertically integrating the hydrostatic equation and differentiating with respect to $y$ we find that $p_{y}=-\rho_{y} g(z+F(y))$, where $z=0$ is defined 
to be at the ocean-ice interface and $F(y)$ is an arbitrary function of $y$ so that,

$$
\beta y u=\frac{1}{\rho_{0}} g(z+F(y)) \rho_{y}+\nu_{h} v_{y y} .
$$

It is possible to show that $F(y)=H / 2$, by depth-integrating Eqs. (3),(6), using the fact that the integrated meridional velocity should be zero due to the mass (or volume) conservation, and by assuming that the depth-integrated zonal velocity vanishes at $y \rightarrow \pm \infty^{1}$.

Eqs. (3) and (4) may be solved in terms of Airy functions, but we instead solve them separately for the off-equatorial and equatorial regions and then match the two solutions, leading to a more informative solution. As shown in AGLMST, for the off-equatorial region, the viscosity term in Eq. (4) is negligible compared to the Coriolis term, leading to

$$
u_{\mathrm{oe}}=\frac{g(z+H / 2) \rho_{y}}{\beta \rho_{0}} \frac{1}{y} .
$$

This leads, based on Eq. (3), to the following meridional velocity away from the equator,

$$
v_{\mathrm{oe}}=-\frac{2 g(z+H / 2) \nu_{h} \rho_{y}}{\beta^{2} \rho_{0}} \frac{1}{y^{4}}
$$

where the subscript "oe" stands for "off-equatorial". Based on Eqs. (7), (8), it is clear that: (i) both the zonal $(u)$ and meridional $(v)$ velocities decay away from the equator, where $v$ decays much faster than $u$; (ii) $u$ is anti-symmetric about the equator, while $v$ is symmetric; and (iii) both $u$ and $v$ change signs at the mid-ocean depth, $z=-H / 2$.

In the equatorial region, the Coriolis term is negligible in the meridional momentum balance, while it still balances eddy viscosity in the zonal momentum equation, so that Eqs. $(3,4)$ become

$$
\begin{aligned}
\nu_{h} u_{\mathrm{e}, y y}+\beta y v_{e} & =0 \\
\frac{1}{\rho_{0}} g(z+H / 2) \rho_{y}+\nu_{h} v_{\mathrm{e}, y y} & =0
\end{aligned}
$$

\footnotetext{
${ }^{1}$ The integration of Eqs. (3),(6) leads to $-\beta y V=\nu_{h} U_{y y}=0$ and hence $U=\rho_{y} g H(F(y)-H / 2) /\left(\rho_{0} \beta y\right)$ where $U, V$ are the vertically integrated velocities. Thus $V=0$ and $U$ must be a linear function of $y$. Since $U$ must vanish when $y \rightarrow \pm \infty, F(y)=H / 2$ and hence $U=0$ for every $y$.
} 
where the subscript "e" denotes the equatorial solution. These balances were verified from the numerical solution, and it was found that the eddy viscosity term indeed varies linearly in latitude around the equator. Continuing to assume, for simplicity, that the pressure gradient term is approximately constant in latitude near the equator, the solution is a second-order polynomial for $v$ and a fifth-order polynomial for $u$. Requiring that the equatorial and off-equatorial solutions match continuously at some latitude $y_{0}$ one finds,

$$
\begin{aligned}
& u_{\mathrm{e}}=\frac{g \beta \rho_{y}(z+H / 2)}{40 \rho_{0} \nu_{h}^{2}} y_{0}^{5}\left[\frac{y^{5}}{y_{0}^{5}}+\left(\frac{40 \nu_{h}^{2}}{3 \beta^{2} y_{0}^{6}}-\frac{10}{3}\right) \frac{y^{3}}{y_{0}^{3}}+\left(\frac{80 \nu_{h}^{2}}{3 \beta^{2} y_{0}^{6}}+\frac{7}{3}\right) \frac{y}{y_{0}}\right], \\
& v_{\mathrm{e}}=-\frac{g \rho_{y}(z+H / 2)}{2 \rho_{0} \nu_{h}} y_{0}^{2}\left(\frac{y^{2}}{y_{0}^{2}}+\frac{4 \nu_{h}^{2}}{\beta^{2}} \frac{1}{y_{0}^{6}}-1\right) .
\end{aligned}
$$

It is clear that $u_{\mathrm{e}}$ is anti-symmetric in latitude, while $v_{\mathrm{e}}$ is symmetric, as in the off-equatorial region. The matching point between the off-equatorial and the equatorial velocities, $y_{0}$, can be found by requiring that the derivative of the zonal velocity is continuous at $y_{0}$ as well, giving,

$$
y_{0}=40^{1 / 6}\left(\frac{\nu_{h}}{\beta}\right) \text {. }
$$

Using $y_{0}$, the overall solution is

$$
u(y)= \begin{cases}\frac{g \beta \rho_{y}(z+H / 2)}{40 \rho_{0} \nu_{h}^{2}} y_{0}^{5}\left(\frac{y^{5}}{y_{0}^{5}}-3 \frac{y^{3}}{y_{0}^{3}}+3 \frac{y}{y_{0}}\right), & |y|<y_{0} \\ \frac{g(z+H / 2) \rho_{y}}{\beta \rho_{0}} \frac{1}{y}, & |y| \geq y_{0}\end{cases}
$$

$$
v(y)= \begin{cases}\frac{g \rho_{y}(z+H / 2)}{2 \rho_{0} \nu_{h}} y_{0}^{2}\left(\frac{9}{10}-\frac{y^{2}}{y_{0}^{2}}\right), & |y|<y_{0} \\ -\frac{2 g(z+H / 2) \nu_{h} \rho_{y}}{\beta^{2} \rho_{0}} \frac{1}{y^{4}}, & |y| \geq y_{0}\end{cases}
$$

The vertical velocity can be found from the continuity equation

$$
w(y)= \begin{cases}\frac{g \rho_{y}}{2 \rho_{0} \nu_{h}}\left((z+H / 2)^{2}-\frac{H^{2}}{4}\right) y, & |y|<y_{0} \\ -\frac{4 g \nu_{h} \rho_{y}}{\beta^{2} \rho_{0}}\left((z+H / 2)^{2}-\frac{H^{2}}{4}\right) \frac{1}{y^{5}}, & |y| \geq y_{0}\end{cases}
$$

Note that $w$ is not continuous at $y_{0}$.

The half-width of the MOC cell, $y_{1}$, can be estimated by finding the location at which the meridional velocity vanishes and is

$$
y_{1}=\frac{3}{\sqrt{10}} y_{0}
$$


The maximum meridional velocity $v_{\max }$ is found at the equator, either at the top or the bottom of the ocean as

$$
v_{\max }=\frac{9 g \rho_{y} H}{40 \rho_{0} \nu_{h}} y_{0}^{2} .
$$

The mean meridional velocity within the MOC cell boundaries is

$$
\langle v\rangle=\frac{2}{3} v_{\max } .
$$

The maximal zonal velocity $u_{\max }$ can be shown to be either at the surface or bottom of the ocean with a value of

$$
u_{\max } \approx 0.44 v_{\max }
$$

at $y^{*}= \pm y_{0} \sqrt{(9-\sqrt{21}) / 10} \approx \pm 0.66 y_{0}$.

The MOC stream function $\psi(y, z)$ can be found by integrating $v(y, z)=-\psi_{z}$ as

$$
\psi(y, z)=\frac{g \rho_{y}}{4 \rho_{0} \nu_{h}} y_{0}^{2}\left(\frac{y^{2}}{y_{0}^{2}}-\frac{9}{10}\right)\left((z+H / 2)^{2}-\frac{H^{2}}{4}\right),
$$

such that the stream function vanishes at the top $(z=0)$ and bottom $(z=-H)$ of the ocean. The maximum of the stream function is at mid-ocean depth at the equator (i.e., $y=0$ and $z=-H / 2)$ and is found to be

$$
\psi_{\max }=\frac{H}{4} v_{\max } .
$$

The stream function $\mathrm{MOC}$, in $\mathrm{Sv}$, is obtained by multiplying the above stream function by the Earth's perimeter.

The solution presented above accounts for nearly all the characteristics of the numerical properties listed at the end of section 3. Namely: (i) the zonal velocity is anti-symmetric in latitude (vanishing at the equator), and the meridional velocity is symmetric (maximal at the equator); (ii) horizontal velocities obtain their maximum absolute value at the bottom and the top of the ocean and change signs with depth; (iii) velocities decay away from the equator, and the decay is faster for the meridional velocity; (iv) the meridional extent of the MOC cell and its maximal value at the mid-depth at the equator are well predicted; and 
(v) vertical velocity shows upwelling north of the equator, downwelling south of the equator, zero at the equator, and the maximal vertical velocity at the mid-depth of the ocean. The length scale associated with the dynamics depends on the horizontal viscosity and the $\beta$ Coriolis parameter. While $\beta$ is well defined, the horizontal viscosity is unknown for Snowball conditions. In our simulations, we used a value that is comparable to present day values for $1^{\circ}$ resolution models; for larger horizontal viscosity, the approximations above (neglecting the advection terms and vertical viscosity) become even more accurate. Horizontal viscosity that is consistent with mixing length estimates, based on a high resolution, eddy resolving 1/8 of a degree calculations for the Snowball ocean AGLMST, yielded a higher value.

While the extent of the MOC cell is well constrained (by $\nu_{h}$ and $\beta$ ), its magnitude and the magnitude of the velocities depend on the meridional density gradient, $\rho_{y}$, which we assumed to be roughly constant and specified (from the numerical solution) near the equator. We now attempt to develop a rough approximation for this density gradient, completing the above discussion.

We integrate the time independent, zonally symmetric, salinity equation $(v S)_{y}+(w S)_{z}=$ $\kappa_{v} S_{z z}+\kappa_{h} S_{y y}$ from bottom to top and from the southern boundary of the MOC cell (i.e., from $y=-y_{1}$ given in Eq. (17)) to the equator $(y=0)$, where we assume $v S \approx 0$ and $\kappa_{h} S_{y} \approx 0$ at the southern edge of the MOC cell. We then use the surface boundary conditions $-\kappa_{v} S_{z}=S_{0} q / \rho_{0}$ where $q$ is the freshwater flux due to ice melting/ freezing (in $\mathrm{kg} \mathrm{m}^{-2} \mathrm{~s}^{-1}$ ), finding $H^{-1} \int d z\left(v S-\kappa_{h} S_{y}\right)=H^{-1} \int d y q S_{0} / \rho_{0}=\left(y_{1} / H\right) q S_{0} / \rho_{0}$; here we assume a constant melting rate difference, $q$, over the MOC cell. Since the salinity contribution to density variations dominates that of the temperature, we can multiply the equation by $\beta_{S} \rho_{0}$ (where $\beta_{S}=7.73 \times 10^{-4}$ is the haline coefficient) to find an equation for the potential density,

$$
\frac{1}{H} \int_{-H}^{0} d z\left(\kappa_{h} \rho_{y}-v \rho\right) \approx \kappa_{h} \rho_{y}-v_{\max }\left(\rho_{y} y_{1}\right)=\beta_{S} S_{0} q y_{1} / H \approx \frac{\beta_{S} S_{0} M \delta}{\lambda H},
$$

where $v_{\max }$ is the maximal meridional velocity (18). The freshwater flux over the MOC cell may be related to the difference between the maximal geothermal heating and that of the equator, $\delta$ (in $\mathrm{W} \mathrm{m}^{-2}$ ) as follows: $q \approx M \delta /\left(y_{1} \lambda\right)$, where $\lambda=334000 \mathrm{~J} \mathrm{~kg}^{-1}$ is the latent heat 
of fusion and $M$ is the distance between the central heating and the equator. The above is based on the ice-shelf equations of the MITgcm (Losch 2008). Since $v_{\max }$ depends on $\rho_{y}$, it is necessary to solve a quadratic equation to find $\rho_{y}{ }^{2}$. Following the above, we obtain the following expression for $\rho_{y}$,

$$
\rho_{y}=\frac{10 \rho_{0} \kappa_{h} \beta}{27 g H}\left(1-\sqrt{1+\frac{27 \delta g M \beta_{S} S_{0}}{5 \lambda \kappa_{h}^{2} \rho_{0} \beta}}\right) .
$$

\section{Sensitivity tests of the $2 \mathrm{D}$ solution}

We now present the results of sensitivity experiments for the latitude-depth 2D ocean configuration, having two objectives in mind: (1) to examine the robustness of the results discussed above, and (2) to examine the predictive power and accuracy of the analytic approximations presented in section 4 .

\section{a. Sensitivity of the 2D numerical solution}

The latitude-depth profiles of the temperature, salinity, meridional velocity, and the MOC of the standard run and of the following sensitivity experiments are shown in Fig. 2 (from the top row downward). All experiments started from the standard case described in section 3, with modifications from that configuration as follows,

i. Without a ridge. The geothermal heating is as in the standard case.

ii. With the ridge and the geothermal heating centered at the equator.

iii. Same as ii, including enhanced equatorial heating, but without the ridge.

\footnotetext{
${ }^{2}$ It is possible to find the velocities when the density gradient is parabolic $\left(\rho=\gamma_{\rho} y^{2}\right)$ rather than linear. In this case, in off-equatorial regions, the meridional velocity is zero, while the zonal velocity is constant and equals to $g z / \gamma_{\rho} / \beta \rho_{0}$. Such an approximation is useful when geothermal heating is concentrated at the equator, a situation that, most probably, does not resemble Snowball conditions.
} 
iv. With the ridge and geothermal heating located at $40^{\circ} \mathrm{N}$ instead of $20^{\circ} \mathrm{N}$.

v. With mean geothermal heating of $0.075 \mathrm{~W} / \mathrm{m}^{2}$ instead of $0.1 \mathrm{~W} / \mathrm{m}^{2}$.

There are several common characteristics to the steady state solutions in all experiments. First, the spatial variations in ice thickness do not exceed $100 \mathrm{~m}$. Second, the temperature and salinity are nearly independent of depth. Third, the ocean circulation is centered around the equator, where the MOC cell is only a few degrees of latitude wide. Fourth, the zonal velocity close to the bottom has an opposite sign from the zonal velocity at the top of the ocean. All the above features are similar to those of the standard run and in agreement with the analytic approximations presented in section 4 . This indicates that the solutions shown and analyzed above are indeed robust and represent a wide range of geometries and forcing fields.

As expected, the warmest and freshest waters are located close to the location of enhanced geothermal heating. Still, the equatorial ocean response (velocities and MOC) is not sensitive to the location of the ridge or geothermal heating once the heating is located outside the tropics (top, fourth, and bottom rows of Fig. 2). This is expected from the analytic approximation, presented above, that basically depends on the density gradient across the equator, which does not change dramatically when the ridge and heating are located at different latitudes outside the equatorial region.

However, when the ridge and/or geothermal heating are located exactly at the equator (second and third rows of Fig. 2), the density gradient exactly at the equator is almost zero, and the equatorial water depth is affected by the ridge. In these cases, the zonal velocity does not change signs across the equator, as in all the other, off-equatorial heating experiments. This is consistent with a parabolic density profile, which may be analyzed similarly to the linear profile discussed in section 4. The zonal and meridional velocities still change signs with depth in this case, and are still limited to near the equator. Moreover, the MOC in the absence of an equatorial ridge (third row of Fig. 2) is about four times larger compared to the case with the equatorial ridge (second row of Fig. 2), consistent with the 
analytic approximation [Eqs. (21),(22)] that predicts that the MOC intensity will increase as a function of the water depth at the equator. In the case of equatorial heating, the system is symmetric, and the MOC can be either clockwise (second row of Fig. 2) or counterclockwise (third row of Fig. 2). We did not observe a solution with two equatorial MOC cells in these 2D latitude-depth experiments, although in principle such a situation may be possible.

When the mean geothermal heating is reduced from 0.1 to $0.075 \mathrm{~W} / \mathrm{m}^{2}$ (bottom row of Fig. 2), the ice becomes thicker by about $25 \%$ and the circulation is weaker compared to the standard case, due to the weaker meridional density gradient that results from the weaker geothermal heating gradients.

In addition to the above experiments, we also performed an experiment without a ridge and with uniform geothermal heating; these changes led to an MOC cell of $\sim 8 \mathrm{~Sv}$, significantly weaker than the standard case. This experiment suggests that the atmospheric temperature, which is now the only source of meridional gradients in melting and freezing, is responsible for about one quarter of the MOC intensity, as the circulation with localized geothermal heating is about $35 \mathrm{~Sv}$. When using uniform atmospheric temperature and uniform geothermal heating, the circulation vanishes. We also initialized the model with present day salinity (35 ppt) and two times the present day salinity (70 ppt), and obtained a circulation that is similar to the standard run; these salinity sensitivity experiments suggest that the dynamics of Snowball ocean do not strongly depend on the mean salinity.

\section{b. A broader exploration of parameter space}

To examine the range of applicability of the analytic approximations presented in section 4, we used an idealized configuration and large parameter variations, covering and exploring a large regime in the parameter space.

In the reference experiment of this set, the ice thickness was kept constant in time and space (i.e., the ocean was not coupled to the ice-flow model); the ice thickness was set to $1124 \mathrm{~m}$ so that the base of the ice was $1124 \times \rho_{i} / \rho_{w}=1011 \mathrm{~m}$, as heat diffusion through this 
ice thickness exactly balances a mean geothermal heat flux of $0.1 \mathrm{~W} / \mathrm{m}^{2}$, based on a globally averaged ice-surface temperature; we used a flat ocean bottom (no ridge), a geothermal heat flux as for the standard case discussed above with the difference between the maximal heating and background heating of $\Delta Q=0.225 \mathrm{~W} / \mathrm{m}^{2}$ (i.e., mean geothermal heating of $0.1 \mathrm{~W} / \mathrm{m}^{2}$ with enhanced heating concentrated around $20^{\circ} \mathrm{N}$, at which the maximal heating is four times larger than the background), a horizontal viscosity of $\nu_{h}=2 \times 10^{5} \mathrm{~m}^{2} \mathrm{~s}^{-1}$, a vertical viscosity of $\nu_{v}=2 \times 10^{-3} \mathrm{~m}^{2} \mathrm{~s}^{-1}$, horizontal and vertical diffusion coefficients of temperature and salinity of $\kappa_{h}=2000 \mathrm{~m}^{2} \mathrm{~s}^{-1}$ and $\kappa_{v}=2 \times 10^{-4} \mathrm{~m}^{2} \mathrm{~s}^{-1}$, and an ocean depth of $H=2000 \mathrm{~m}$. We used a latitude-depth configuration with a meridional extent from $84^{\circ} \mathrm{S}$ to $84^{\circ} \mathrm{N}$ and $2^{\circ}$ resolution (the edge grid points are assumed to be land points); 21 vertical levels were used, with an upper level, completely embedded within the ice, having thickness of $1 \mathrm{~km}$ and additional 20 levels, each of them $100 \mathrm{~m}$ thick. The different experiments were run until a steady state was reached.

We performed the following experiments, all starting from the reference experiment described above with the following modifications,

1. Reference experiment as described above.

2. Ten times deeper ocean, $10 H$.

3. Ten times shallower ocean, $H / 10$.

4. Uniform geothermal heat flux, $\Delta Q=0$.

5. Difference between the maximal geothermal heat flux and the background of $3 \Delta Q \approx 0.608$ $\mathrm{W} / \mathrm{m}^{2}$; the maximum heat flux is 18 times larger than the background.

6. Rotation that is $1 / 4$ of the Earth's rotation; i.e., the $\beta$-plane coefficient becomes $\beta / 4$.

7. Rotation that is $1 / 9$ of Earth's rotation; i.e., the $\beta$-plane coefficient becomes $\beta / 9$.

8. Sixteen times larger horizontal viscosity coefficient, $16 \nu_{h}$. 
469

470

471 12. Sixteen times larger horizontal viscosity coefficient, $16 \nu_{h}$, and four times larger horizontal 472 diffusion coefficient, $4 \kappa_{h}$.

473 13. Four times larger horizontal viscosity coefficient, $4 \nu_{h}$, and four times larger horizontal 474 475

9. Four times smaller horizontal viscosity coefficient, $\nu_{h} / 4$.

10. Four times larger horizontal diffusion coefficient, $4 \kappa_{h}$.

11. Four times smaller horizontal diffusion coefficient, $\kappa_{h} / 4$. diffusion coefficient, $4 \kappa_{h}$.

14. Ten times smaller vertical diffusion coefficient, $\kappa_{v} / 10$.

15. Four times smaller horizontal viscosity coefficient, $\nu_{h} / 4$, and a four times smaller horizontal diffusion coefficient, $\kappa_{h} / 4$.

The results of these numerical experiments are compared with the analytical scaling solutions in Fig. 3. As the horizontal eddy viscosity becomes larger, the analytic approximations become more accurate, as the neglected momentum advection terms become even smaller than the horizontal eddy viscosity term. Four measures were considered: maximum zonal velocity, maximum meridional velocity, maximum MOC, and half-width of the MOC cell. All four measures yielded a good correlation between numerical experiments and analytic expressions with a correlation coefficient higher than or equal to 0.87 , pointing to a good correspondence between the analytic approximations and the numerical results. Yet, there are systematic quantitative biases in the analytic results relative to the numerical solutions. The predicted maximal zonal velocity is more than two times smaller than the numerical one, while the predicted maximal meridional velocity is about $30 \%$ larger than the numerical one. In the analytic approximation, the maximal zonal velocity is $44 \%$ of the maximal meridional velocity, while in the numerical simulations, the maximal zonal velocity is larger than $67 \%$ of the maximal meridional velocity. Similarly, the predicted maximal MOC is $30 \%$ larger than the numerical one. The difference between the numerical and analytic approximations 
may be attributed to the terms neglected in the analytic approximation, to the piece-wise analytic solution (solving for the equatorial and off-equatorial regions instead of solving for both simultaneously using Airy and hypergeometrical functions), and to the assumption of a linear latitudinal density gradient.

We found a relatively high correlation coefficient of 0.95 for the comparison between the half-width of the MOC cell of the numerical results and the numerical approximation. Still, the MOC cell width is larger in the numerical results by about 50\%. According to the analytic approximation, the half-width in the MOC cell only depends on the horizontal viscosity and the $\beta$ parameter (i.e., it is proportional to $\left.\left(\nu_{h} / \beta\right)^{1 / 3}\right)$-other parameters, such as the density gradient, $\rho_{y}$, which may be associated with larger uncertainties, do not appear in the expression for the width of the MOC cell. This high correlation coefficient strengthens the first part of the analytic approximation, which can be obtained once a specific density gradient $\rho_{y}$ is given.

Our scaling estimate of the density gradient $\rho_{y}$ (Eq. 24) leaves room for improvement. Yet, overall, the analytic approximations provide a reasonable estimate, within factor 2, of the numerical solutions.

\section{3D ocean model solution with a reconstructed Neo- proterozoic continental configuration}

We proceed to describe steady solutions of the 3D near-global ocean model coupled to the 2D ice flow model. Our objective is to examine if and how the insights obtained above, using the 2D ocean model, change due to the added dimension and presence of continents. We can also examine a more realistic geothermal forcing, and study the sensitivity to the geothermal heating and bathymetry that are not well constrained by observations. 
For the simulation using the $3 \mathrm{D}$ ocean model coupled to the $2 \mathrm{D}$ ice flow model, we followed the configuration described in section 2. Our standard 3D run included enhanced localized geothermal heating along spreading centers following Li et al. (2008), as indicated by the solid black contour line in Fig. 4.

The ice thickness and velocity field are shown in Fig. 4a. The ice is generally thicker than $1 \mathrm{~km}$. As in Tziperman et al. (2012), the ice is thinner in the constricted sea area between the land masses, both due to the ice sublimation and melting there (see below) and due to the reduced ice flow into this region due to the friction with the land masses. The differences in ice thickness can reach $240 \mathrm{~m}$, significantly more than in the $1 \mathrm{D}$ case without continents (Campbell et al. 2011; Tziperman et al. 2012). As expected, the general ice flow is directed from the high latitudes towards the equator (i.e., from snow/ice accumulation areas to ice sublimation/melting areas) with a velocity of up to $35 \mathrm{~m} \mathrm{y}^{-1}$ in the region of the constricted sea.

The temperature, salinity, and density fields close to the base of the ice cover are shown in Fig. 4. The warmest and freshest waters are found within the constricted sea area (Fig. 4), due to the enhanced warming and melting in this region associated with the localized geothermal heating. Thus, the surface water is lighter in this region (bottom right panel of Fig. 4). As in the $2 \mathrm{D}$ simulation described in section 3 , temperature and salinity are almost independent of depth in most areas, except very close to the ice in the constricted sea area. This confirms the assumption of a vertically uniform density used in the analytic derivations of section 4 , as well as the assumption of density variations, mostly in the meridional direction. The differences in temperature, salinity, and density in the 3D simulations are smaller than those of the $2 \mathrm{D}$ simulations. This is a result of the zonally restricted region of enhanced geothermal heating, relative to the latitudinal band of heating prescribed in the 2D case.

In contrast to the temperature and salinity, whose distribution can be directly linked to geothermal heating, the velocities of the 3D simulations are concentrated near the equator 
(Fig. 5), similar to the zonally symmetric $2 \mathrm{D}$ results (Figs. 1,2). The continents do not inhibit the formation of strong equatorial zonal jets. Also similar to the $2 \mathrm{D}$ results, and as predicted by the analytic expressions, the zonal and meridional velocities change signs with depth and the vertical velocity does not. Yet, the latitudinal symmetry properties of the 3D run are somewhat different from those of the 2D standard run shown in Fig. 1 and the top panel of Fig. 2, as further discussed below.

Fig. 5 shows that the continents have some effect on the currents - currents, in particular the equatorial zonal jets, that either encounter the continents or flow away from them lead to boundary currents and to upwelling and downwelling close to the continents. The weak salinity stratification over the enhanced geothermal heating regions allows some heating of the deep water to occur, and the upwelling of warmer, geothermally heated, bottom water near the continents. The latter can lead to enhanced melting, especially at high model resolution (AGLMST). However, the coarse resolution of the current model, the absence of detailed continental-shelf bathymetry, and the inability of our ice-flow model to handle bottom bathymetry do not allow us to draw more specific conclusions on the implications for the existence of open water (a potential refuge for photosynthetic life) due to this upwelling.

A very close similarity between the zonally symmetric model and the more realisticgeometry 3D simulation is seen in the zonal mean temperature, salinity and velocity fields of the 3D run (Fig. 6). The tracers are vertically well mixed and are almost independent of depth; where the ocean is weakly stratified, there is a "cap" of fresh and warm water due to the heating and melting in the vicinity of the geothermal heating. The temperature and salinity range in the ocean interior are only about $0.15^{\circ} \mathrm{C}$ and $0.05 \mathrm{ppt}$, respectively, leading to a density range of $0.06 \mathrm{~kg} \mathrm{~m}^{-3}$.

The zonal mean velocities (Fig. 6) are concentrated around the equator as in the 2D case, but their latitudinal symmetry properties are somewhat different from those of the standard 2D run, described in sections 3 and 4 and shown in Fig. 2. It is possible to see two opposite zonal jets at the equator, just below the ice. However, below these jets, the zonal velocity 
converges into a single symmetric jet that is similar to the one in the equatorially heated case shown in Fig. 2. The zonal jet changes its sign with depth as before. The meridional velocity also exhibits a different symmetry compared to the standard 2D simulations in Figs. 1,2. In the $3 \mathrm{D}$ case, the meridional velocity is almost symmetric in latitude just below the ice and becomes anti-symmetric below that, indicating the presence of two opposite MOC cells with poleward velocity at the upper ocean. The meridional velocity also changes sign with depth. The vertical velocity is consistent with the equatorial cells formed by the meridional velocity, with rising motion at the equator.

The two MOC cells (Fig. 7) - a southern, counterclockwise cell, with a maximum flux of $15 \mathrm{~Sv}$ and a northern, clockwise cell, with a maximum flux of $20 \mathrm{~Sv}$ - are weaker than in the standard 2D run (section 3 and Figs. 1,2), although the range of the stream function of 36 $\mathrm{Sv}$ is similar to that seen in the $2 \mathrm{D}$ standard run. The extent of the cells is several degrees latitude, as for the standard 2D run, and as predicted by the analytic approximation. We will show below that the presence of the two cells is a result of the presence of continents.

\section{b. 3D sensitivity to bathymetry and geothermal heat flux distribution}

The bathymetry of the Neoproterozoic is poorly constrained, and in order to examine the robustness of our results with respect to this factor, we performed three additional 3D-ocean/2D-ice-flow sensitivity runs based on the standard 3D run described in previous subsection a: Run (i) uses a uniform geothermal heat flux of $0.1 \mathrm{~W} \mathrm{~m}^{-2}$, run (ii) has a $1 \mathrm{~km}$ high sill between the continents around the constricted sea area, and run (iii) has the same sill as run (ii) and additional zonal and meridional mid-ocean ridges that are also regions of enhanced geothermal heating (the mean geothermal heat flux is again $0.1 \mathrm{~W} \mathrm{~m}^{-2}$ ).

A summary of the results (potential density and MOC) of the three experiments is shown in Fig. 8. In experiment (i), the freshest water is not in the vicinity of the constricted sea (as in the standard case shown in Fig. 4), but at the low latitudes of the open ocean, due to the elimination of the enhanced melting region within the constricted sea. Because we 
removed the differential geothermal heating, the difference in density is smaller compared to the standard case. The zonal mean potential density is almost uniform with depth, as for the $2 \mathrm{D}$ and $3 \mathrm{D}$ results presented above. The MOC is concentrated around the equator as before; the details of the MOC are different though, due to the uniform heat flux. The existence of two cells in both the standard 3D run and in Experiment (i) confirms that the existence of two MOC cells is due to the presence of the continents rather than the locally enhanced geothermal heat flux in the standard run.

The additional sill of $1 \mathrm{~km}$ height between the continents in Experiment (ii) leads to a similar circulation and density pattern as for the 3D standard run (middle row of Fig. 8), although the MOC is weaker because the bottom water circulation is blocked in the region of the constricted sea. The presence of sills also alters the location of the freshest water.

One expects mid-ocean ridges to have extents that are roughly similar to those of the present day. Experiment (iii), with such ridges specified, in necessarily arbitrary locations, and with enhanced geothermal heat flux over these ridges, resulted in a circulation and density field that are similar to the standard 3D run (bottom panels of Fig. 8). Here, however, the MOC cell is stronger due to the larger heating in the $\mathrm{NH}$ (over the high $\mathrm{NH}$ latitude ridge).

Finally, an additional 3D run, similar to the standard 2D run (discussed in section 3), with no continents and with a global configuration, led to results that were almost identical to those of the $2 \mathrm{D}$ standard run.

\section{Summary and conclusions}

We find that the steady circulation under a thick $(\sim 1000 \mathrm{~m})$ ice cover in a Snowball Earth scenario is composed of an equatorial MOC and zonal jets. The MOC amplitude is comparable to the present day North Atlantic MOC, yet is restricted to within a couple of degrees latitude around the equator. These results are supported by 2D (latitude-depth) and 
3D simulations with an ocean GCM. These are found to be robust with respect to geometry and forcing parameters, and are consistent with analytical approximations derived from the equations of motion. The analytic solution indicates that a horizontal equatorial density gradient leads to a pressure gradient that, in turn, drives the MOC and zonal jets. Eddy viscosity plays an important role in these dynamics, determining the meridional extent of the MOC.

Given that the temperature, salinity and density are essentially vertically uniform in nearly all locations, due to convective instability driven by the geothermal heat flux, we chose not to use eddy parameterizations developed for the very different modern-day ocean (Gent and McWilliams 1990). Instead, we use a simple formulation with constant strictly horizontal and vertical eddy coefficients. The horizontal eddy viscosity and eddy mixing coefficients are smaller than the ones predicted by a high resolution eddy resolving run (AGLMST); the results of that runs confirm our results. Note that larger viscosity and diffusion coefficients lead to a better agreement with the analytical prediction. An alternative approach was taken by Ferreira et al. (2011) (their appendix C), who used the GM scheme and found strong eddy-driven high latitude meridional cells, different from the equatorial circulation found here. While their run is not at a steady state due to the lack of geothermal heat flux and their ice cover is only $200 \mathrm{~m}$ thick, these results are very interesting and suggest that further study of the role of eddies in a Snowball ocean is worthwhile. Such a study, in a dynamical regime very far from that of the present-day ocean, may lead to new insights on eddy dynamics that may enrich our understanding of ocean dynamics in modern conditions as well.

An important goal of studying snowball ocean circulation is to aid geologists and geochemists in the interpretation of the geological, geochemical and paleontological record. Geochemical studies sometimes assume that the ocean was stagnant and not well mixed. The first important lesson from the present study is that one expects the ocean to be well mixed in the vertical nearly everywhere, as indicated by the vertically uniform tempera- 
ture and salinity profiles, due to the geothermal heat flux. The second related lesson is the presence of a relatively strong zonal circulation and meridional overturning circulation which would have together further mixed the ocean horizontally and vertically. Ferreira et al. (2011) also found a very weak stratification and strong MOC cells, although at higher latitudes rather than at the equator as found here. But it does seem that the snowball ocean needs to be thought of as well mixed rather than stagnant, and that one cannot assume the deep water to be disconnected from the surface ocean. It is, admittedly, difficult to come up with additional specific insights that are directly relevant to the observed record, and it may take future geochemical studies to explore the consequences of the circulation and stratification reported here. It is worth noting that much of the present study dealt with the large scale ocean circulation in deep ocean basins, while the preserved geological record is mostly from shelf and shallow areas that have not been subducted by now. We do note that our study identifies strong tendency for near-coast upwelling and downwelling, as a result of a combination of the weak stratification and the encounter of horizontal (mostly zonal) currents and land masses, and this may have some geological relevance as well.

\section{Acknowledgments.}

We thank Aiko Voigt and an anonymous reviewer for their most helpful comments. This work was supported by NSF Climate Dynamics, P2C2 Program, grant ATM-0902844 (ET, YA) and NSF Climate Dynamics Program, grant ATM-0917468 (ET). ET thanks the Weizmann Institute for its hospitality during parts of this work. YA thanks the Harvard EPS Department for a most pleasant and productive sabbatical visit. 


\section{Scaling of idealized 2D configuration}

We start from the $\beta$-plane momentum equations under the assumptions of steady state (i.e., $\partial_{t}=0$ and zonal symmetry $\partial_{x}=0$ )

$$
\begin{aligned}
v u_{y}+w u_{z}-\beta y v & =\nu_{h} u_{y y}+\nu_{v} u_{z z} \\
v v_{y}+w v_{z}+\beta y u & =-\frac{1}{\rho_{0}} p_{y}+\nu_{h} v_{y y}+\nu_{v} v_{z z}
\end{aligned}
$$

It is possible to switch to nondimensional variables as follows: $y=\left(\nu_{h} / \beta\right)^{1 / 3} \hat{y}, z=H \hat{z}$ ( $H$ is the depth of the ocean), $p=g H \rho_{y}\left(\nu_{h} / \beta\right)^{1 / 3} \hat{p}, u=\left(g H \rho_{y}\right) /\left(\rho_{0} \beta^{2 / 3} \nu_{h}^{1 / 3}\right) \hat{u}, v=$ $\left(g H \rho_{y}\right) /\left(\rho_{0} \beta^{2 / 3} \nu_{h}^{1 / 3}\right) \hat{v}, w=\left(g H^{2} \rho_{y}\right) /\left(\rho_{0} \beta^{1 / 3} \nu_{h}^{2 / 3}\right) \hat{w}$, where the hat indicates nondimensional variables. Then Eqs. (A1)-(A2) become:

$$
\begin{aligned}
& \varepsilon_{1} \hat{v} \hat{u}_{\hat{y}}+\varepsilon_{1} \hat{w} \hat{u}_{\hat{z}}-\hat{y} \hat{v}=\hat{u}_{\hat{y} \hat{y}}+\varepsilon_{2} \hat{u}_{\hat{z} \hat{z}}, \\
& \varepsilon_{1} \hat{v} \hat{v}_{\hat{y}}+\varepsilon_{1} \hat{w} \hat{v}_{\hat{z}}+\hat{y} \hat{u}=-\hat{p}_{\hat{y}}+\hat{v}_{\hat{y} \hat{y}}+\varepsilon_{2} \hat{v}_{\hat{z} \hat{z}} .
\end{aligned}
$$

where

$$
\begin{aligned}
\varepsilon_{1} & =\frac{g H \rho_{y}}{\rho_{0} \beta n u_{h}} \ll 1, \\
\varepsilon_{2} & =\frac{\nu_{v}}{H^{2} \beta^{2 / 3} n u_{h}^{1 / 3}} \ll 1,
\end{aligned}
$$

are small parameters under our choice of parameters, $\approx 8 \times 10^{-3}, \approx 2 \times 10^{-5}$ respectively. Thus, it is possible to neglect the advection and vertical viscosity terms from the momentum equations. 


\section{REFERENCES}

Abbot, D., A. Voigt, and D. Koll, 2011: The Jormungand global climate state and implications for Neoproterozoic glaciations. J. Geophys. Res., 116, D18 103.

Abbot, D. S. and I. Halevy, 2010: Dust aerosol important for snowball earth deglaciation. J. Climate, 23 (15), 4121-4132.

Abbot, D. S. and R. T. Pierrehumbert, 2010: Mudball: Surface dust and snowball earth deglaciation. J. Geophys. Res., 115.

Abbot, D. S., A. Voigt, M. Branson, R. T. Pierrehumbert, D. Pollard, G. Le Hir, and D. D. Koll, 2012: Clouds and Snowball Earth deglaciation. Geophys. Res. Lett., 39, L20 711.

Allen, P. A. and J. L. Etienne, 2008: Sedimentary challenge to snowball earth. Nature Geoscience, 1, 817.

Ashkenazy, Y., H. Gildor, M. Losch, F. A. Macdonald, D. P. Schrag, and E. Tziperman, 2013: Dynamics of a Snowball Earth ocean. Nature, 495, 90-93, doi:10.1038/nature11894.

Baum, S. and T. Crowley, 2001: Gcm response to late precambrian (similar to 590 ma) ice-covered continents. Geophys. Res. Lett., 28 (4), 583-586, doi:10.1029/2000GL011557.

Baum, S. and T. Crowley, 2003: The snow/ice instability as a mechanism for rapid climate change: A Neoproterozoic Snowball Earth model example. Geophys. Res. Lett., 30 (20), doi:10.1029/2003GL017333.

Bryan, K., 1984: Accelerating the convergence to equilibrium of ocean-climate models. J. Phys. Oceanogr., 14, 666-673. 
Budyko, M. I., 1969: The effect of solar radiatin variations on the climate of the earth. Tellus, 21, 611-619.

Campbell, A. J., E. D. Waddington, and S. G. Warren, 2011: Refugium for surface life on Snowball Earth in a nearly-enclosed sea? A first simple model for sea-glacier invasion. Geophys. Res. Lett., 38, 10.1029/2011GL048 846.

Chandler, M. A. and L. E. Sohl, 2000: Climate forcings and the initiation of low-latitude ice sheets during the Neoproterozoic Varanger glacial interval. J. Geophys. Res., 105 (D16), $20737-20756$.

Crowley, T. and S. Baum, 1993: Effect of decreased solar luminosity on late Precambrian ice extent. J. Geophys. Res., 98 (D9), 16 723-16 732, doi:10.1029/93JD01415.

Donnadieu, Y., F. Fluteau, G. Ramstein, C. Ritz, and J. Besse, 2003: Is there a conflict between the Neoproterozoic glacial deposits and the snowball Earth interpretation: an improved understanding with numerical modeling. Earth Planet. Sci. Lett., 208 (1-2), $101-112$.

Donnadieu, Y., Y. Godderis, G. Ramstein, A. Nedelec, and J. Meert, 2004a: A 'snowball Earth' climate triggered by continental break-up through changes in runoff. Nature, 428 (6980), 303-306.

Donnadieu, Y., G. Ramstein, F. Fluteau, D. Roche, and A. Ganopolski, 2004b: The impact of atmospheric and oceanic heat transports on the sea-ice-albedo instability during the Neoproterozoic. Clim. Dyn., 22 (2-3), 293-306.

Evans, D. A. D. and T. D. Raub, 2011: Neoproterozoic glacial palaeolatitudes: a global update. The Geological Record of Neoproterozoic Glaciations, E. Arnaud, G. P. Halverson, and G. Shields-Zhou, Eds., London, Geological Society of London, Vol. 36, 93-112. 
Ferreira, D., J. Marshall, and B. E. J. Rose, 2011: Climate determinism revisited: multiple equilibria in a complex climate model. J. Climate, 24, 992-1012.

Gent, P. R. and J. C. McWilliams, 1990: Isopycnal mixing in ocean circulation models. J. Phys. Oceanogr., 20 (1), 150-155.

Goodman, J. C., 2006: Through thick and thin: Marine and meteoric ice in a "Snowball Earth" climate. Geophys. Res. Lett., 33 (16).

Goodman, J. C. and R. T. Pierrehumbert, 2003: Glacial flow of floating marine ice in "Snowball Earth". J. Geophys. Res., 108 (C10).

Harland, W. B., 1964: Evidence of late Precambrian glaciation and its significance. Problems in Palaeoclimatology, A. E. M. Nairn, Ed., John Wiley \& Sons, London, 119-149, 180-184.

Hoffman, P. and D. Schrag, 2002: The snowball Earth hypothesis: testing the limits of global change. Terra Nova, 14 (3), 129-155, doi:10.1046/j.1365-3121.2002.00408.x.

Hyde, W. T., T. J. Crowley, S. K. Baum, and W. R. Peltier, 2000: Neoproterozoic 'snowball earth' simulations with a coupled climate/ice-sheet model. Nature, 405, 425-429.

Jackett, D. R. and T. J. McDougall, 1995: Minimal adjustment of hydrographic profiles to achieve static stability. J. Atmos. Ocean Tech., 12 (4), 381-389.

Jenkins, G. and S. Smith, 1999: Gcm simulations of snowball earth conditions during the late proterozoic. Geophys. Res. Lett., 26 (15), 2263-2266, doi:10.1029/1999GL900538.

Kirschvink, J. L., 1992: Late Proterozoic low-latitude glaciation: the snowball Earth. The Proterozoic Biosphere, J. W. Schopf and C. Klein, Eds., Cambridge University Press, Cambridge, 51-52.

Knauth, L., 2005: Temperature and salinity history of the Precambrian ocean: implications for the course of microbial evolution. Paleonogr. Paleoclim. Paleoecol., 219, 53-69. 
Langen, P. L. and V. A. Alexeev, 2004: Multiple equilibria and asymmetric climates in the ccm3 coupled to an oceanic mixed layer with thermodynamic sea ice. Geophys. Res. Lett., 31, L04 201.

Le-Hir, G., Y. Donnadieu, G. Krinner, and G. Ramstein, 2010: Toward the snowball earth deglaciation... Clim. Dyn., 35 (2-3), 285-297, doi:10.1007/s00382-010-0748-8.

Le-Hir, G., G. Ramstein, Y. Donnadieu, and R. T. Pierrehumbert, 2007: Investigating plausible mechanisms to trigger a deglaciation from a hard snowball Earth. Comptes rendus - Geosci., 339 (3-4), 274-287, doi:10.1016/j.crte.2006.09.002.

Lewis, J., M. Eby, A. Weaver, S. Johnston, and R. Jacob, 2004: Global glaciation in the neoproterozoic: Reconciling previous modelling results. Geophys. Res. Lett., 31 (8), doi: 10.1029/2004GL019725.

Lewis, J. P., A. J. Weaver, and M. Eby, 2007: Snowball versus slushball Earth: Dynamic versus nondynamic sea ice? J. Geophys. Res., 112.

Lewis, J. P., A. J. Weaver, S. T. Johnston, and M. Eby, 2003: Neoproterozoic "snowball Earth": Dynamic sea ice over a quiescent ocean. Paleoceanography, 18 (4).

Li, D. and R. T. Pierrehumbert, 2011: Sea glacier flow and dust transport on Snowball Earth. Geophys. Res. Lett., 38, 10.1029/2011GL048 991.

Li, Z. X., et al., 2008: Assembly, configuration, and break-up history of Rodinia: A synthesis. Precambrian Res., 160, 179-210.

Losch, M., 2008: Modeling ice shelf cavities in a z-coordinate ocean general circulation model. J. Geophys. Res., 113, C08043.

MacAyeal, D., 1997: EISMINT: Lessons in ice-sheet modeling. Tech. rep., University of Chicago, Chicago, Illinois. 
Macdonald, F. A., et al., 2010: Calibrating the Cryogenian. Science, 327 (5970), 1241-1243.

Marotzke, J. and M. Botzet, 2007: Present-day and ice-covered equilibrium states in a comprehensive climate model. Geophys. Res. Lett., 34, L16 704.

Marshall, J., A. Adcroft, C. Hill, L. Perelman, and C. Heisey, 1997: A finite-volume, incompressible Navier Stokes model for studies of the ocean on parallel computers. J. Geophys. Res., 102, C3, 5,753-5,766.

McKay, C. P., 2000: Thickness of tropical ice and photosynthesis on a snowball Earth. Geophys. Res. Lett., 27 (14), 2153-2156.

Micheels, A. and M. Montenari, 2008: A snowball Earth versus a slushball Earth: Results from Neoproterozoic climate modeling sensitivity experiments. Geosphere, 4 (2), 401-410.

Morland, L., 1987: Unconfined ice-shelf flow. Dynamics of the West Antarctic Ice Sheet, C. van der Veen and J. Oerlemans, Eds., D. Reidel, Boston.

Pierrehumbert, R. T., 2002: The hydrologic cycle in deep-time climate problems. Nature, 419 (6903), 191-198.

Pierrehumbert, R. T., 2004: High levels of atmospheric carbon dioxide necessary for the termination of global glaciation. Nature, 429 (6992), 646-649.

Pierrehumbert, R. T., 2005: Climate dynamics of a hard snowball Earth. J. Geophys. Res., $110(\mathrm{D} 1)$.

Pierrehumbert, R. T., D. S. Abbot, A. Voigt, and D. Koll, 2011: Climate of the neoproterozoic. Ann. Rev. of Earth and Planet. Sci., 39, 417-460.

Pollack, H., S. Hurter, and J. Johnson, 1993: Heat flow from the Earth's interior: analysis of the global data set. Rev. Geophys., 31, 267-280. 
Pollard, D. and J. Kasting, 2004: Climate-ice sheet simulations of Neoproterozoic glaciation before and after collapse to Snowball Earth. Geophysical Monograph series, 146, 91-105.

Pollard, D. and J. F. Kasting, 2005: Snowball Earth: A thin-ice solution with flowing sea glaciers. J. Geophys. Res., 110 (C7).

Pollard, D. and J. F. Kasting, 2006: Reply to comment by Stephen G. Warren and Richard E. Brandt on "Snowball Earth: A thin-ice solution with flowing sea glaciers". J. Geophys. Res., 111 (C9), doi:10.1029/2006JC003488.

Poulsen, C., R. T. Pierrehumbert, and R. L. Jacobs, 2001a: Impact of ocean dynamics on the simulation of the Neoproterozoic "snowball Earth". Geophys. Res. Lett., 28, 1575-1578.

Poulsen, C. J. and R. L. Jacob, 2004: Factors that inhibit snowball Earth simulation. Paleoceanography, 19 (4).

Poulsen, C. J., R. L. Jacob, R. T. Pierrehumbert, and T. T. Huynh, 2002: Testing paleogeographic controls on a Neoproterozoic snowball Earth. Geophys. Res. Lett., 29 (11).

Poulsen, C. J., R. T. Pierrehumbert, and R. L. Jacob, 2001b: Impact of ocean dynamics on the simulation of the Neoproterozoic "snowball Earth". Geophys. Res. Lett., 28 (8), $1575-1578$.

Romanova, V., G. Lohmann, and K. Grosfeld, 2006: Effect of land albedo, co2, orography, and oceanic heat transport on extreme climates. Climate of the Past, 2 (1), 31-42.

Rose, B. E. J. and J. Marshall, 2009: Ocean heat transport, sea ice, and multiple climate states: Insights from energy balance models. J. Atmos. Sci., 66 (9), 2828-2843.

Schrag, D. P., R. A. Berner, P. F. Hoffman, and G. P. Halverson, 2002: On the initiation of a snowball Earth. Geochemistry Geophysics Geosystems, 3, doi:10.1029/2001GC000219.

Schrag, D. P., P. F. Hoffman, W. Hyde, et al., 2001: Life, geology and snowball earth. NATURE-LONDON-, 306-306. 
Sellers, W., 1969: A global climate model based on the energy balance of the Earthatmosphere system. J. Appl. Meteorol., 8, 392-400.

Sohl, L. E. and M. A. Chandler, 2007: Reconstructing Neoproterozoic palaeoclimates using a combined data/modelling approach. Deep-Time Perspectives on Climate Change: Marrying the Signal from Computer Models and Biological Proxies, M. M. Williams, A. M. Hatwood, J. Gregory, and D. N. Schmidt, Eds., Geological Society, Micropalaeontological Society Special Publication \#2, 61-80.

Stein, C. A. and S. Stein, 1992: A model for the global variation in oceanic depth and heat flow with lithospheric age. Nature, 359, 123-129.

Tziperman, E., D. S. Abbot, Y. Ashkenazy, H. Gildor, D. Pollard, C. Schoof, and D. P. Schrag, 2012: Continental constriction and sea ice thickness in a Snowball-Earth scenario. J. Geophys. Res., 117 (C05016), 10.1029/2011JC007 730.

Tziperman, E., I. Halevy, D. T. Johnston, A. H. Knoll, and D. P. Schrag, 2011: Biologically induced initiation of Neoproterozoic Snowball-Earth events. Proc. Natl. Acad. Sci. U.S.A., 108 (37), 1509115 096, doi/10.1073/pnas.1016361 108.

Voigt, A. and D. S. Abbot, 2012: Sea-ice dynamics strongly promote Snowball Earth initiation and destabilize tropical sea-ice margins. Clim. Past, 8, 2079-2092.

Voigt, A., D. S. Abbot, R. T. Pierrehumbert, and J. Marotzke, 2011: Initiation of a Marinoan Snowball Earth in a state-of-the-art atmosphere-ocean general circulation model. Clim. Past, 7, 249-263, doi:10.5194/cp-7-249-2011.

Voigt, A., I. M. Held, and J. Marotzke, 2012: Hadley cell dynamics in a virtually dry snowball earth atmosphere. J. Atmos. Sci., 69 (1), 116-128.

Voigt, A. and J. Marotzke, 2010: The transition from the present-day climate to a modern Snowball Earth. Climate Dynamics, 35 (5), 887-905. 
Warren, S. G. and R. E. Brandt, 2006: Comment on "Snowball Earth: A thin-ice solution with flowing sea glaciers" by David Pollard and James F. Kasting. J. Geophys. Res., 111 (C9), 10.1029/2005JC003 411.

Warren, S. G., R. E. Brandt, T. C. Grenfell, and C. P. McKay, 2002: Snowball Earth: Ice thickness on the tropical ocean. J. Geophys. Res., 107 (C10).

Weertman, J., 1957: Deformation of floating ice shelves. J. Glaciology, 3 (21), 38-42.

Yang, J., W. P. Peltier, and Y. Hu, 2012a: The initiation of modern soft and hard Snowball Earth climates in CCSM4. Clim. Past, 8, 907918.

Yang, J., W. P. Peltier, and Y. Hu, 2012b: The initiation of modern soft snowball and hard snowball climates in CCSM3. part i: The inuences of solar luminosity, CO2 concentration, and the sea ice/snow albedo parameterization. J. Climate, 25, 2711-2736.

Yang, J., W. R. Peltier, and Y. Hu, 2012c: The initiation of modern "soft snowball" and "hard snowball" climates in CCSM3. part ii: Climate dynamic feedbacks. J. Climate, 25 (8), 2737-2754, doi:10.1175/JCLI-D-11-00190.1. 


\section{List of Figures}

1 (a) Density $\left(\mathrm{kg} \mathrm{m}^{-3}\right)$, (b) the depth derivative of the density $\left(\mathrm{kg} \mathrm{m}^{-4}\right)$, (c) meridional velocity $v\left(\mathrm{~cm} \mathrm{~s}^{-1}\right)$, and (d) vertical velocity $w\left(\mathrm{~cm} \mathrm{~s}^{-1}\right)$, at steady state of the latitude-depth standard run. The white area at the top of the plot represents the ice cover and the white area at the bottom of the panels indicates the ridge that has enhanced geothermal heating. The thick contour line in panels a,b represents the zero contour line of panel b, separating the stable stratification around the equator from the unstable stratification elsewhere. Note that the significant circulation is confined to the equatorial regions.

2 A summary of the latitude-depth 2D profiles of the sensitivity experiments. The four columns show the temperature, salinity, zonal velocity, and MOC (presented between $40^{\circ} \mathrm{S}$ and $40^{\circ} \mathrm{N}$ ). The contour line in the first and second columns separates the vertically stable ocean regions from the unstable ones while the contour line in the third column indicates the zero velocity. First row: standard run, after AGLMST. Second row: same as standard run but without the ridge (the geothermal heat flux is as in the standard case). Third row: same as standard but with ridge and enhanced heating placed at the equator. Fourth row: same as second row but without the ridge (yet with an enhanced equatorial heating). Fifth row: same as standard run but with ridge and enhanced heating centered at $40^{\circ} \mathrm{N}$. Sixth row: same as standard but with mean geothermal heat flux of $0.075 \mathrm{~W} / \mathrm{m}^{2}$ instead of 0.1 . 
3 The analytic approximations vs. the numerical results for the experiments described in the text (Experiment 4 of uniform geothermal heating and uniform ice-surface temperature is not presented as it resulted, as expected, in a stagnant ocean). Top left: maximum zonal velocity $\left(\mathrm{cm} \mathrm{s}^{-1}\right)$. Top right: maximum meridional velocity $\left(\mathrm{cm} \mathrm{s}^{-1}\right)$. Bottom left: maximum MOC (Sv) Bottom right: half-width of the MOC cell (degree latitude). The solid line shows the linear regression where the correlation coefficients are $0.88,0.87,0.87$, and 0.95, for the top-left, top-right, bottom-left, and bottom-right panels, respectively. The dashed line indicates the "identity" line. When assuming that the regression lines cross the $(0,0)$ point the slopes of the curves are 0.56 , $1.47,1.63$, and 0.63 for the top-left, top-right, bottom-left, and bottom-right panels, respectively-the correlation coefficients are the same as the above.

4 Results of the 3D standard run. Ice thickness and ice velocity (top left panel), potential temperature (top right panel), salinity (bottom left panel), and density (bottom right panel), all under the ice, at a depth of $1.2 \mathrm{~km}$. The black solid contour line indicates the location of geothermal heating. Ice-depth temperature and salinity are after AGLMST.

5 Circulation in the standard 3D run. Zonal (upper panels), meridional (middle panels), and vertical (bottom panels) velocities, near the ice bottom (at a depth of $1.1 \mathrm{~km}$, left panels) and at $2.9 \mathrm{~km}$ (right panels).

6 Zonal averages of the 3D standard run of potential temperature (top left), salinity (middle left), density (bottom left), zonal velocity (top right), meridional velocity (middle right), and vertical velocity (bottom right). Solid contour lines indicate positive values while dashed contour lines indicate negative values.

7 The MOC of the 3D standard run. 
8 Results of the 3D sensitivity experiments. Density at a depth of $2.5 \mathrm{~km}$ (left panels), zonal mean density (middle column panels), and MOC (right panels), for standard run but with uniform geothermal heating (upper panels), as for standard run but with sills (middle row panels), and as for standard run but with sills and geothermally heated ridges (bottom panels). The dashed contour lines indicate fresher water. The thick solid contour lines indicate the location of the geothermal heating. 

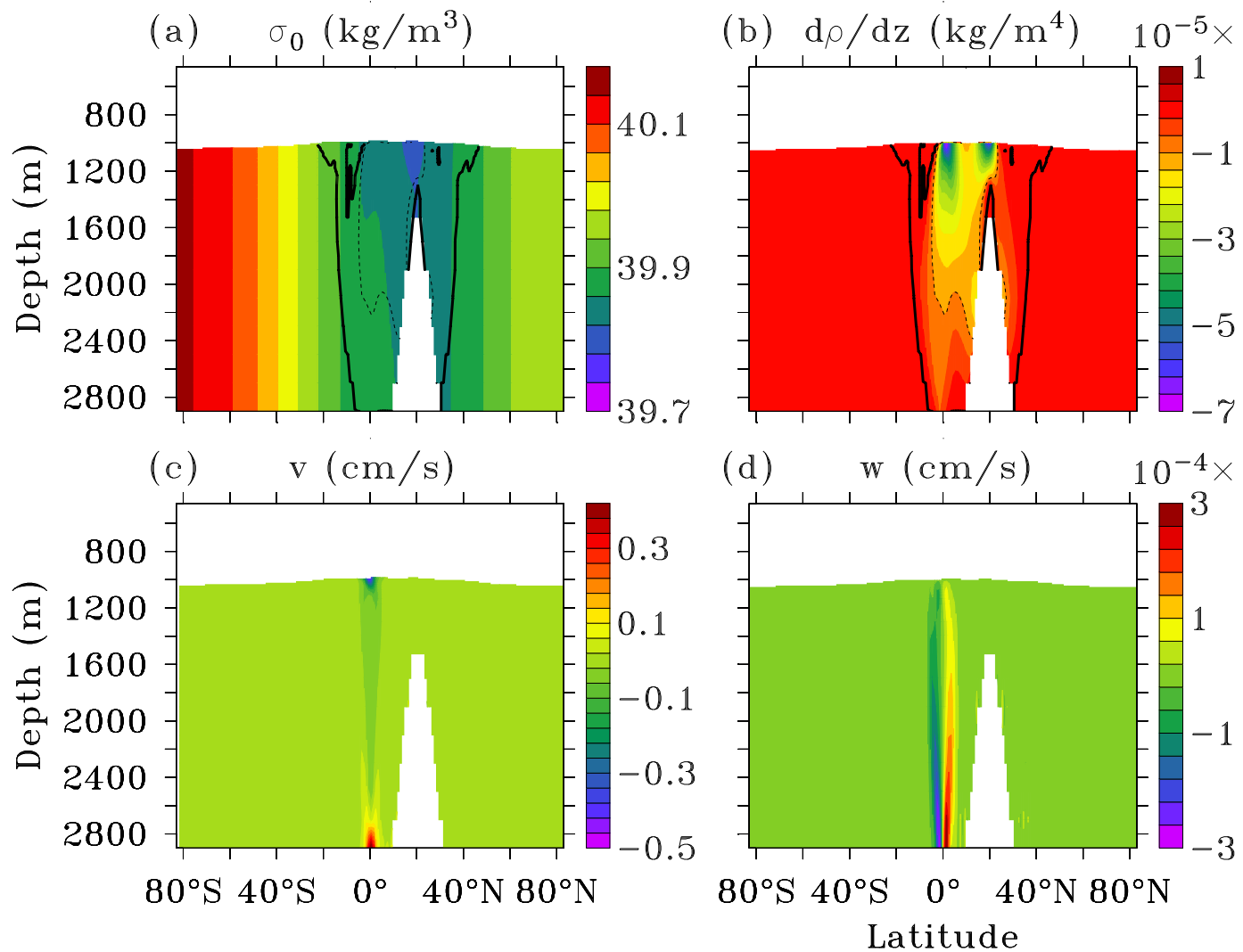

Fig. 1. (a) Density $\left(\mathrm{kg} \mathrm{m}^{-3}\right)$, (b) the depth derivative of the density $\left(\mathrm{kg} \mathrm{m}^{-4}\right)$, (c) meridional velocity $v\left(\mathrm{~cm} \mathrm{~s}^{-1}\right)$, and (d) vertical velocity $w\left(\mathrm{~cm} \mathrm{~s}^{-1}\right)$, at steady state of the latitude-depth standard run. The white area at the top of the plot represents the ice cover and the white area at the bottom of the panels indicates the ridge that has enhanced geothermal heating. The thick contour line in panels a,b represents the zero contour line of panel b, separating the stable stratification around the equator from the unstable stratification elsewhere. Note that the significant circulation is confined to the equatorial regions. 

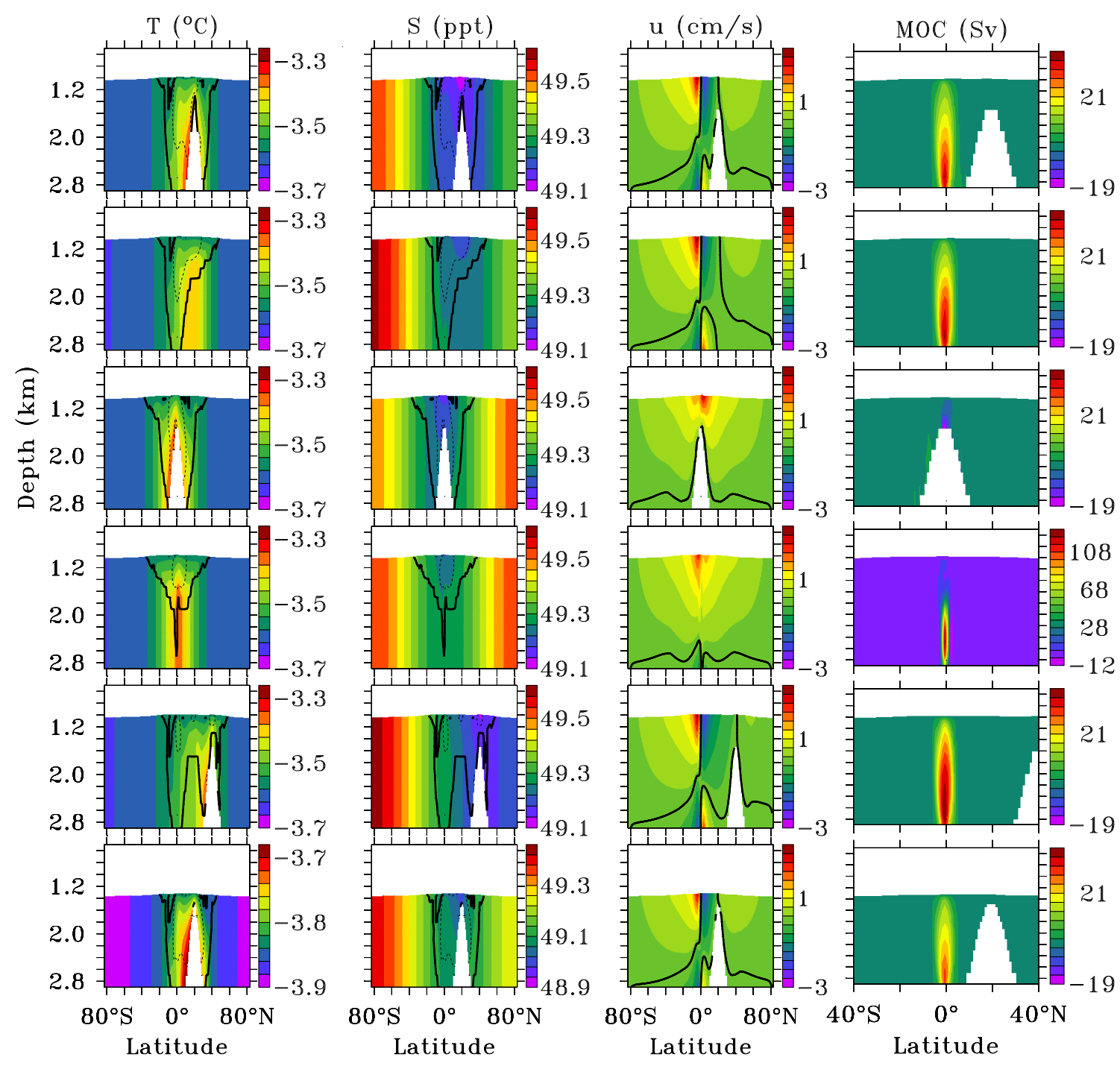

FIG. 2. A summary of the latitude-depth 2D profiles of the sensitivity experiments. The four columns show the temperature, salinity, zonal velocity, and MOC (presented between $40^{\circ} \mathrm{S}$ and $40^{\circ} \mathrm{N}$ ). The contour line in the first and second columns separates the vertically stable ocean regions from the unstable ones while the contour line in the third column indicates the zero velocity. First row: standard run, after AGLMST. Second row: same as standard run but without the ridge (the geothermal heat flux is as in the standard case). Third row: same as standard but with ridge and enhanced heating placed at the equator. Fourth row: same as second row but without the ridge (yet with an enhanced equatorial heating). Fifth row: same as standard run but with ridge and enhanced heating centered at $40^{\circ} \mathrm{N}$. Sixth row: same as standard but with mean geothermal heat flux of $0.075 \mathrm{~W} / \mathrm{m}^{2}$ instead of 0.1 . 

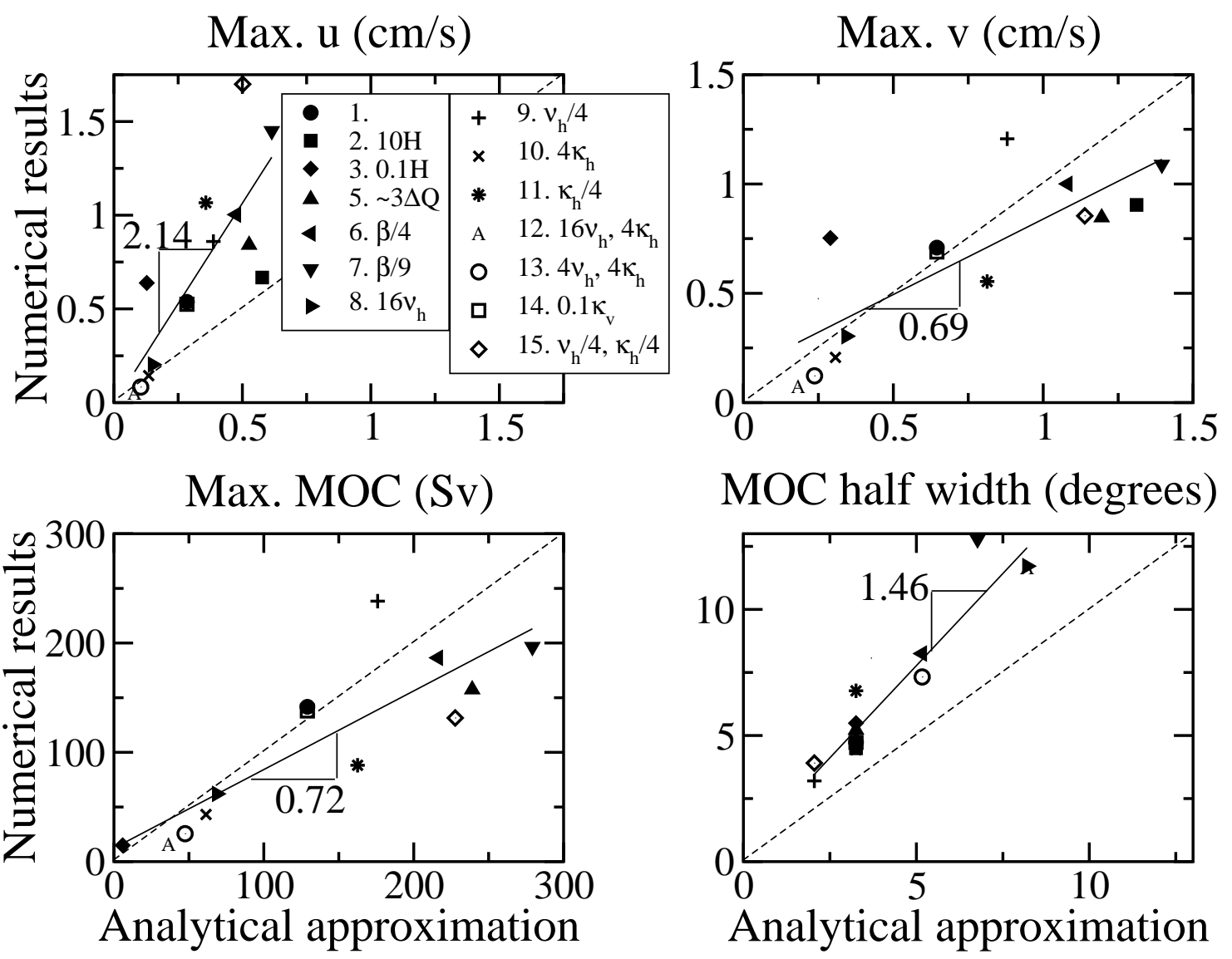

FIG. 3. The analytic approximations vs. the numerical results for the experiments described in the text (Experiment 4 of uniform geothermal heating and uniform ice-surface temperature is not presented as it resulted, as expected, in a stagnant ocean). Top left: maximum zonal velocity $\left(\mathrm{cm} \mathrm{s}^{-1}\right)$. Top right: maximum meridional velocity $\left(\mathrm{cm} \mathrm{s}^{-1}\right)$. Bottom left: maximum MOC (Sv) Bottom right: half-width of the MOC cell (degree latitude). The solid line shows the linear regression where the correlation coefficients are $0.88,0.87,0.87$, and 0.95 , for the top-left, top-right, bottom-left, and bottom-right panels, respectively. The dashed line indicates the "identity" line. When assuming that the regression lines cross the $(0,0)$ point the slopes of the curves are $0.56,1.47,1.63$, and 0.63 for the top-left, top-right, bottom-left, and bottom-right panels, respectively-the correlation coefficients are the same as the above. 

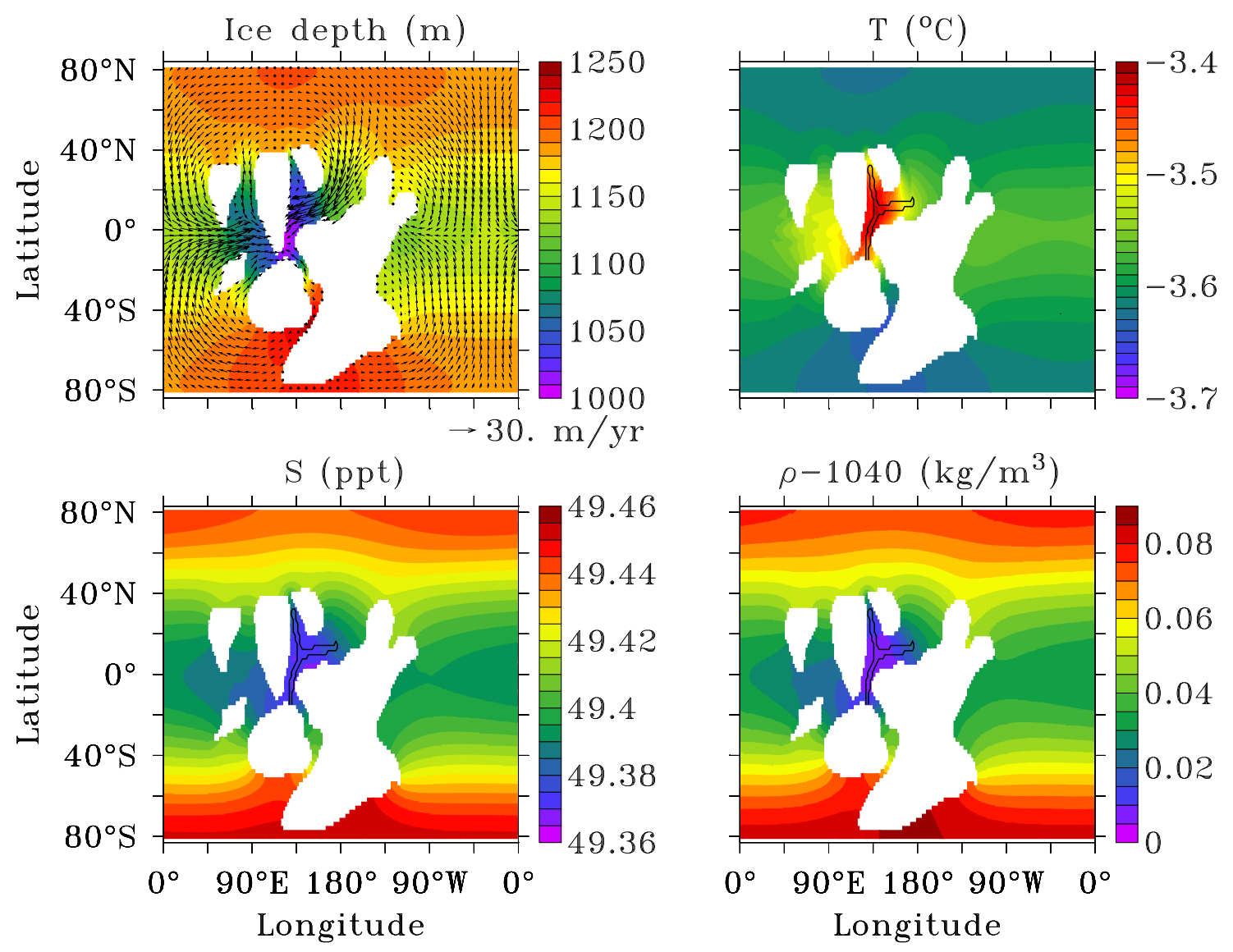

FIG. 4. Results of the 3D standard run. Ice thickness and ice velocity (top left panel), potential temperature (top right panel), salinity (bottom left panel), and density (bottom right panel), all under the ice, at a depth of $1.2 \mathrm{~km}$. The black solid contour line indicates the location of geothermal heating. Ice-depth temperature and salinity are after AGLMST. 

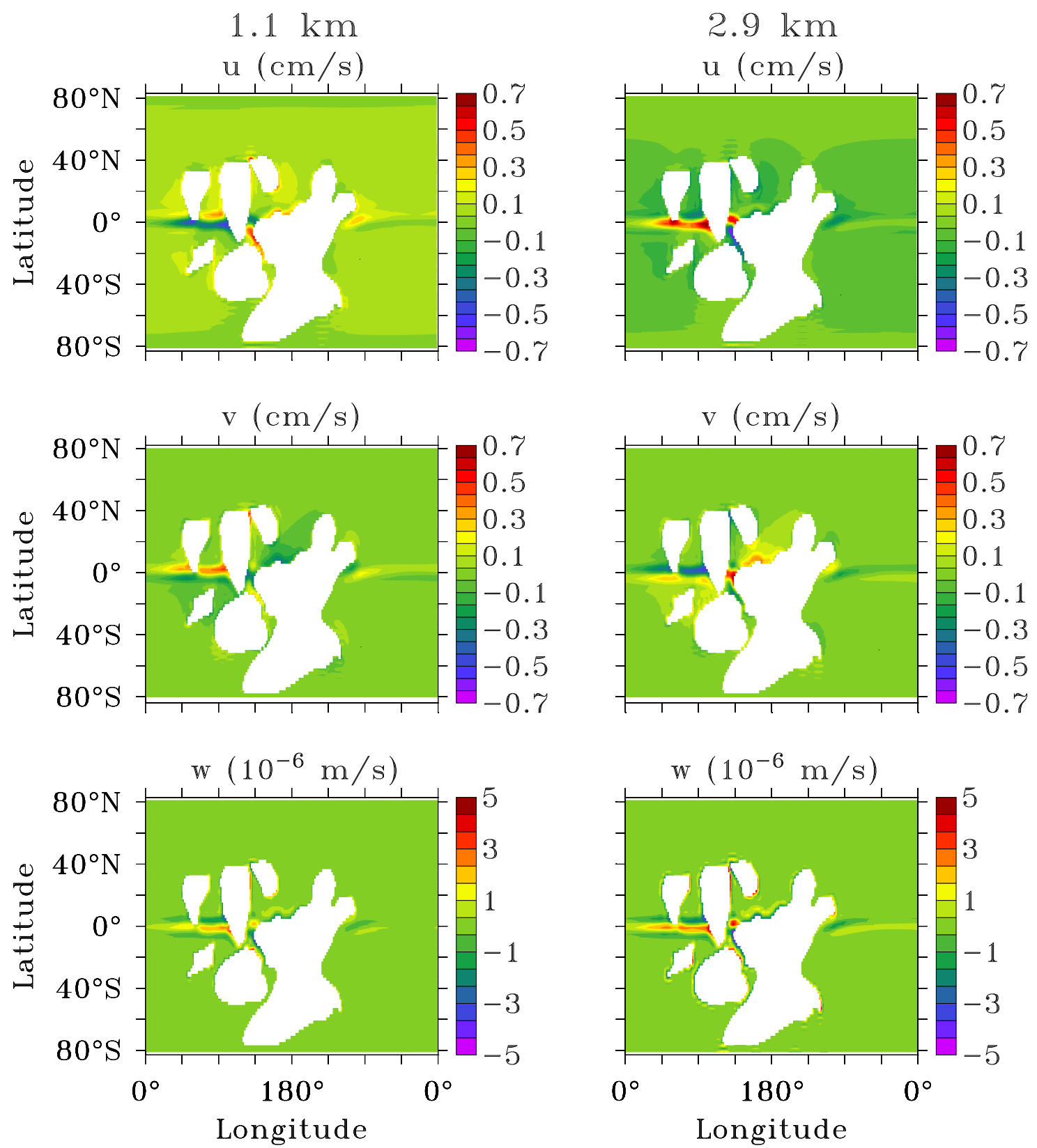

FIG. 5. Circulation in the standard 3D run. Zonal (upper panels), meridional (middle panels), and vertical (bottom panels) velocities, near the ice bottom (at a depth of $1.1 \mathrm{~km}$, left panels) and at $2.9 \mathrm{~km}$ (right panels). 

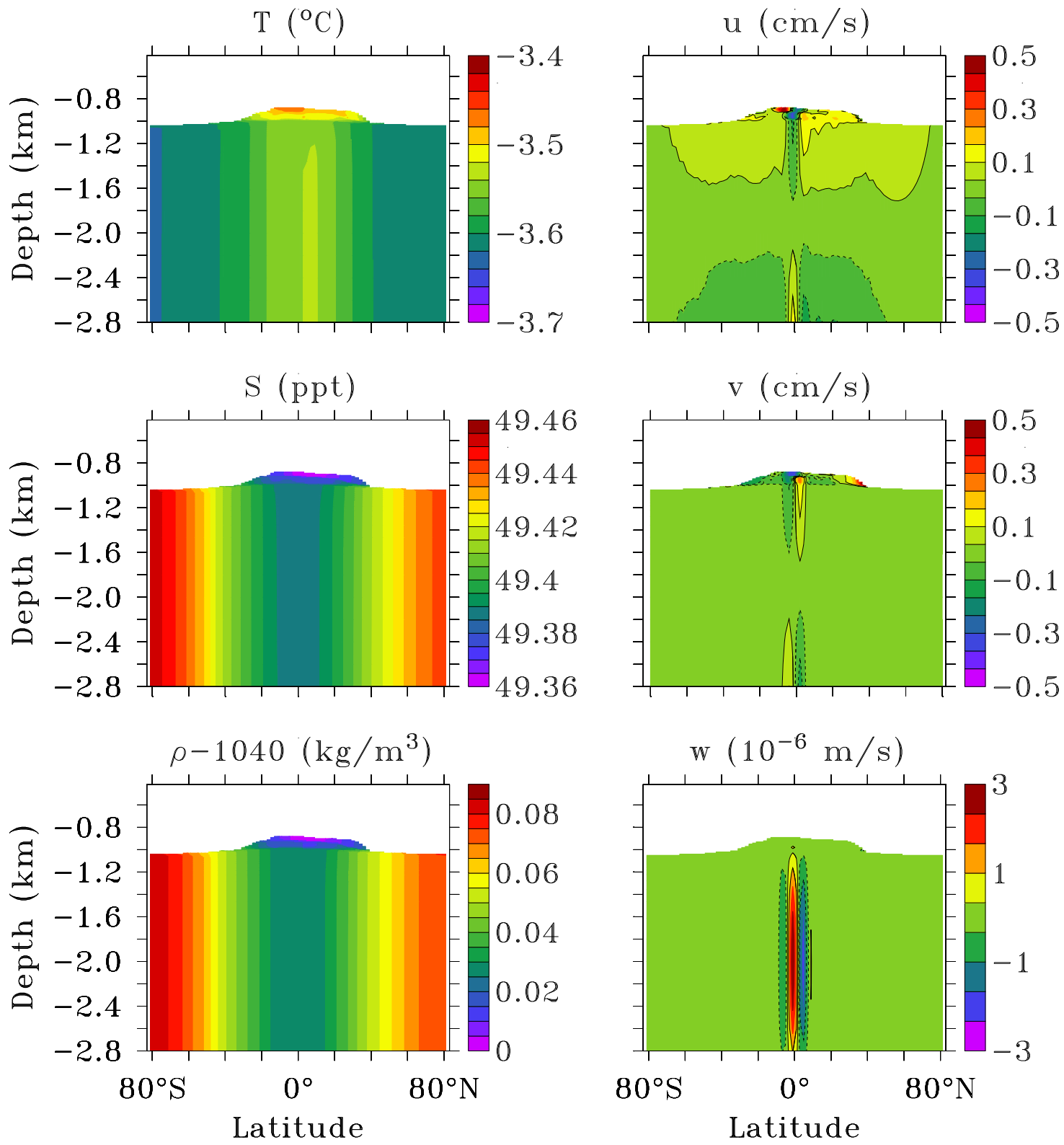

Fig. 6. Zonal averages of the 3D standard run of potential temperature (top left), salinity (middle left), density (bottom left), zonal velocity (top right), meridional velocity (middle right), and vertical velocity (bottom right). Solid contour lines indicate positive values while dashed contour lines indicate negative values. 


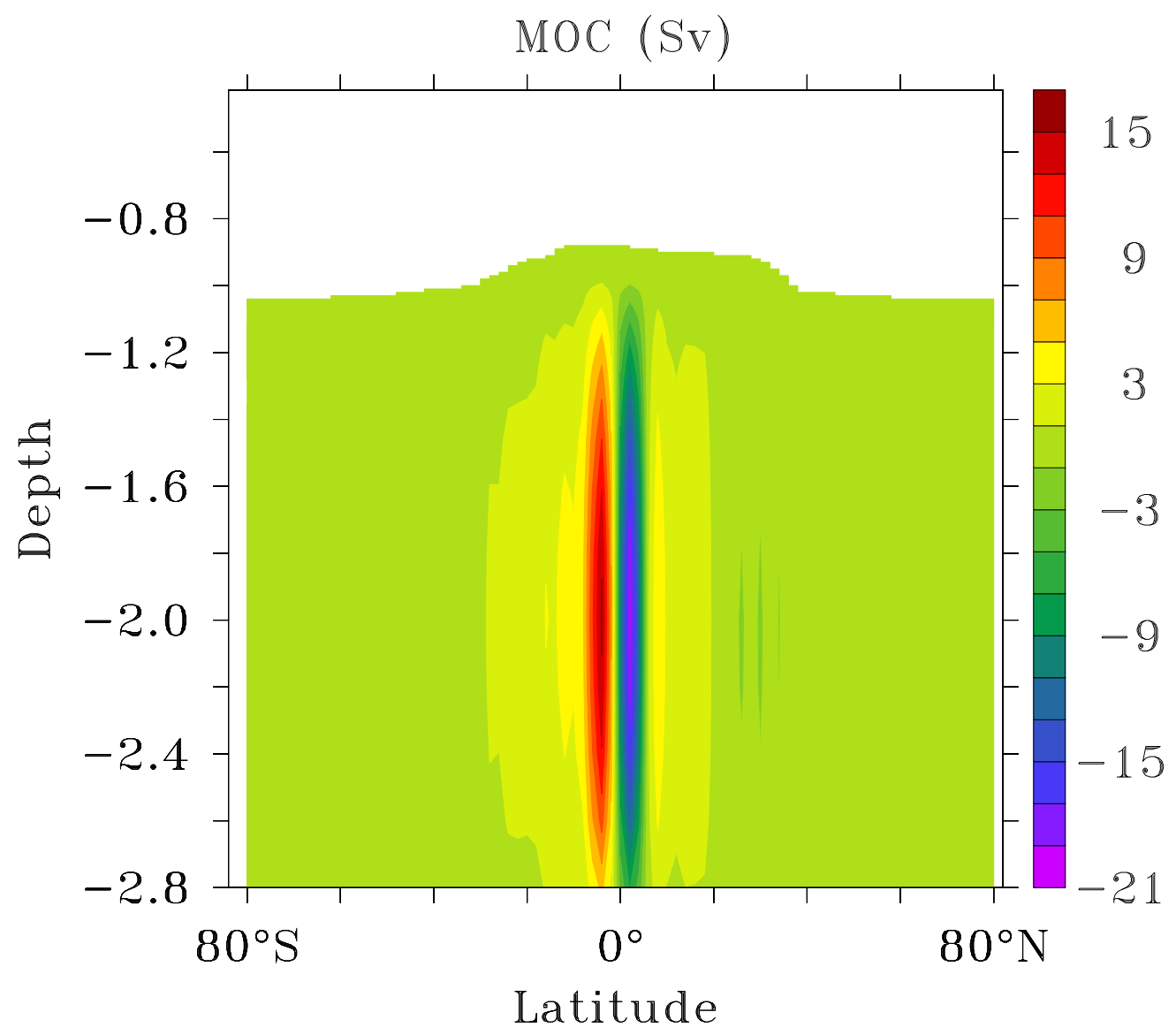

FIG. 7. The MOC of the 3D standard run. 

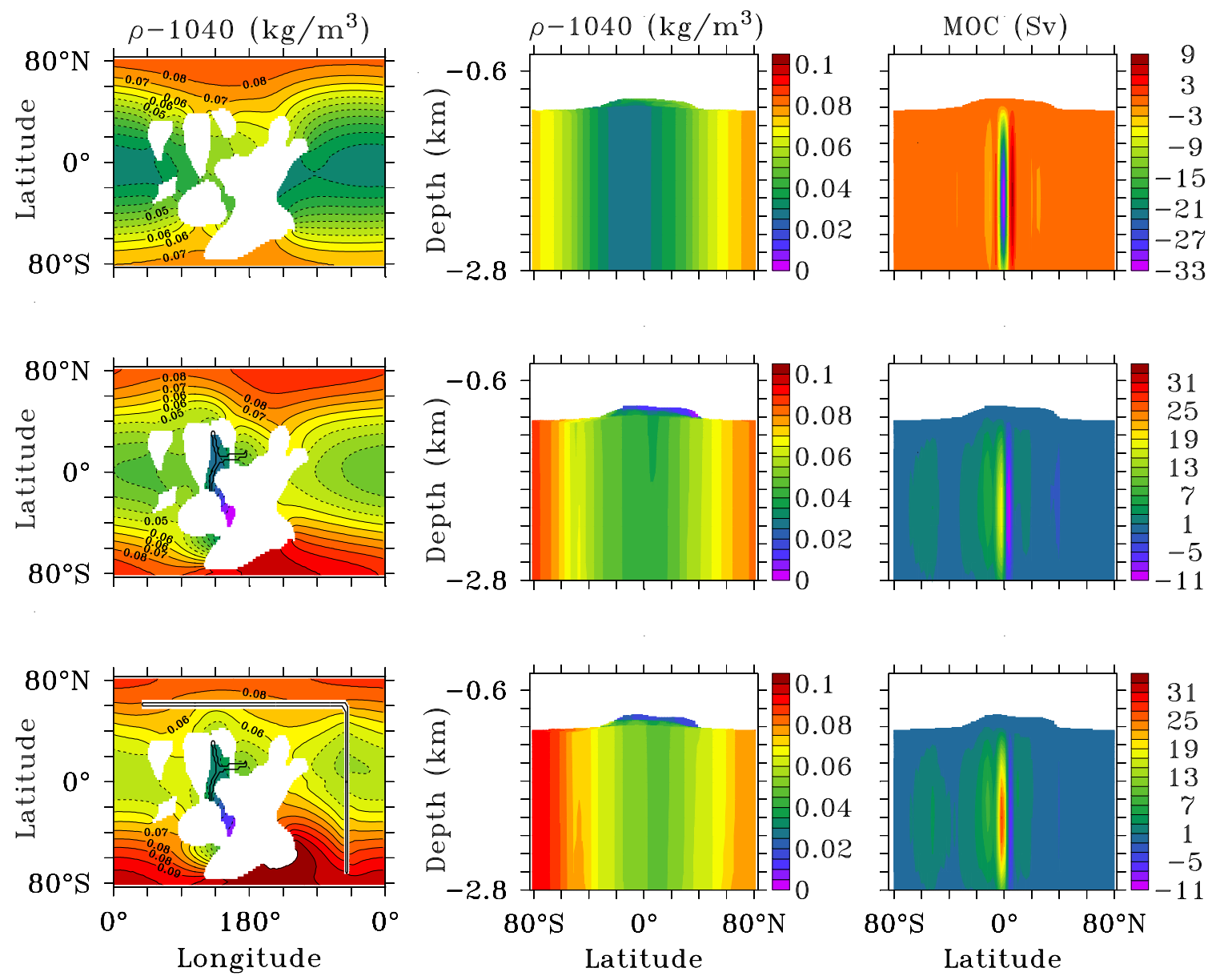

FIG. 8. Results of the 3D sensitivity experiments. Density at a depth of $2.5 \mathrm{~km}$ (left panels), zonal mean density (middle column panels), and MOC (right panels), for standard run but with uniform geothermal heating (upper panels), as for standard run but with sills (middle row panels), and as for standard run but with sills and geothermally heated ridges (bottom panels). The dashed contour lines indicate fresher water. The thick solid contour lines indicate the location of the geothermal heating. 